\title{
A Network Theory of Patentability
}

\author{
Laura G. Pedraza-Fariña† \& Ryan Whalent†
}

Patent law is built upon a fundamental premise: only significant inventions receive patent protection while minor improvements remain in the public domain. This premise is indispensable for maintaining an optimal balance between incentivizing new innovation and providing public access to existing innovation. Despite its importance, the doctrine that performs this gatekeeping role—nonobviousnesshas long remained indeterminate and vague. Judicial opinions have struggled to articulate both what makes an invention significant (or nonobvious) and how to measure nonobviousness in specific cases. These difficulties are due in large part to the existence of two clashing theoretical frameworks, cognitive and economic, that have vied for prominence in justifying nonobviousness. Neither framework, however, has generated doctrinal tests that can be easily and consistently applied.

This Article draws on a novel approach - network theory - to answer both the conceptual question (what is a nonobvious invention?) and the measurement question (how do we determine nonobviousness in specific cases?). First, it shows that what is missing in current conceptual definitions of nonobviousness is an underlying theory of innovation. It then supplies this missing piece. Building upon insights from network science, we model innovation as a process of search and recombination of existing knowledge. Distant searches that combine disparate or weakly connected portions of social and information networks tend to produce high-impact, new ideas that open novel innovation trajectories. Distant searches also tend to be costly and risky. In contrast, local searches tend to result in incremental innovation that is more routine, less costly, and less risky. From a network theory perspective, then, the goal of nonobviousness should be to reward, and therefore to incentivize, those risky

$\dagger \quad J D$, PhD, Associate Professor at Northwestern University Pritzker School of Law.

i† JD, PhD, Assistant Professor in the University of Hong Kong's Faculty of Law. We thank Ronald Allen, Omri Ben-Shahar, Brian Casey, Shari Seidman Diamond, Janet Freilich, Ezra Friedman, Yaniv Heled, William Hubbard, Dmitry Karshtedt, Mark Lemley, Jonathan Masur, Lisa Larrimore Ouellette, Anya Prince, W. Nicholson Price II, Rachel Sachs, Ana Santos Rutschman, David Schwartz, Michal Shur-Ofry, Matthew Spitzer, and Patti Zettler for helpful insights and comments. In addition, we are grateful for feedback from participants at the DePaul University College of Law faculty workshop, Georgetown University Law School Workshop on Empirical Methods and Patents, Georgia State University faculty workshop, Stanford Law School faculty workshop, The University of Chicago Law School law and economics workshop, 2018 Intellectual Property Scholars Conference (IPSC); CREATe Speaker Series at the University of Glasgow; Peking University School of Transnational Law Speaker Series; 2018 Regulation and Innovation in the Biosciences (RIBS) Conference at Washington University; University of ChicagoTsinghua University Young Faculty Forum on Law \& Social Science; and the University of Hong Kong Law \& Technology Speaker Series. We also thank Michael Ellenberger for extraordinary research assistance. 
distant searches and recombinations that produce the most socially significant innovations. By emphasizing factors specific to the structure of innovation-namely, the risks and costs of the search and recombination process-a network approach complements and deepens current economic understandings of nonobviousness. Second, based on our network theory of innovation, we develop an empirical, algorithmic measure of patentability - what we term a patent's "network nonobviousness score" (NNOS). We harness data from US patent records to calculate the distance between the technical knowledge areas recombined in any given invention (or patent), allowing us to assign each patent a specific NNOS. We propose a doctrinal framework that incorporates an invention's NNOS to nonobviousness determinations both at the examination phase and during patent litigation.

Our use of network science to develop a legal algorithm is a methodological innovation in law, with implications for broader debates about computational law. We illustrate how differences in algorithm design can lead to different nonobviousness outcomes, and discuss how to mitigate the negative impact of black box algorithms.

INTRODUCTION .65

I. A Brief History of Nonobviousness Theory AND Doctrine

A. Doctrinal Evolution: From Cognitive to Economic Approaches .78

B. Theoretical Perspectives: Economic and Psychological Models of Nonobviousness

II. Modeling Innovation as a Search and Recombination Process: IMPLICATIONS FOR NONOBVIOUSNESS THEORY AND DOCTRINE.

A. Innovation as Search and Recombination Across Information Networks

B. Network Distance as a Proxy for Market Failures in Innovation.....100

C. Boundary-Crossing Creativity as a Proxy for Market Failures in Innovation 104

D. Examples of a Network Perspective on Innovation .105

III. Developing and Demonstrating a Network Measure of NonOBVIOUSNESS

A. Network Analysis in Legal Research 109

B. Toward a Network Measure of Nonobviousness: Building the Patent Classification Network

C. Constructing and Validating the Network Nonobviousness Score ...115

D. Applied Examples of the Network Nonobviousness Score ................121

1. True negative: Western Union v MoneyGram .............................122

2. False negative: Nike $v$ Adidas.......................................................124

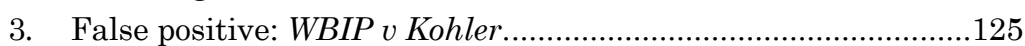

4. True positive: InTouch $v$ VGo. ...................................................127

E. Integrating the Network Nonobviousness Score into the Current Doctrinal Framework .128

1. The "scope and content of the prior art": NNOS as a threshold sorting mechanism

2. Defining the level of skill in the art. 
3. Secondary considerations of nonobviousness 135

F. Advantages and Limitations of a Network Approach........................137

\section{INTRODUCTION}

In the United States, and in every single patent system in the world, one patentability doctrine-the nonobviousness doctrinestands as the cornerstone of the patent bargain. ${ }^{1}$ This bargain ensures that the government only grants the monopoly associated with a patent when the inventor has created something sufficiently different from what came before. ${ }^{2}$ By ensuring that only significant technological improvements obtain patent protection, the nonobviousness doctrine both incentivizes socially significant innovation, and keeps minor technological advances that don't require patent incentives in the public domain. ${ }^{3}$ Without the nonobviousness requirement, patent rights would proliferate until increased licensing fees, litigation expenses, and transaction costs would impede, rather than foster, innovation. ${ }^{4}$

1 See John F. Duffy, Inventing Invention: A Case Study of Legal Innovation, 86 Tex L Rev 1, 6 (2007):

[W]orld patent law has now reached a consensus that the type of invention required for patentability must include some step that is not technically trivial, where triviality is measured by the capabilities of a person skilled in the relevant technical field. This general requirement, which will be referred to here as nonobviousness, is now recognized throughout the world as the essence of invention.

See also Robert M. Hunt, Patentability, Industry Structure, and Innovation, $52 \mathrm{~J}$ Indust Econ 401, 402 (2004) ("When we speak of a standard of patentability in this paper, we focus on American patent law's requirement of nonobviousness, or what is called the inventive step in Europe."); Robert Patrick Merges and John Fitzgerald Duffy, Patent Law and Policy 513 (Carolina Academic 7th ed 2017) ("[N]onobviousness is the 'final gatekeeper of the patent system."').

2 See, for example, Great Atlantic and Pacific Tea Co $v$ Supermarket Equipment Corp, 340 US 147, 152-53 (1950) ("A patent for a combination which only unites old elements with no change in their respective functions . . obviously withdraws what already is known into the field of its monopoly and diminishes the resources available to skillful men.”); KSR International Co v Teleflex Inc, 550 US 398, 427 (2007) (“[A]s progress beginning from higher levels of achievement is expected in the normal course, the results of ordinary innovation are not the subject of exclusive rights under the patent laws.... These premises led to the bar on patents claiming obvious subject matter established in Hotchkiss and codified in §103.”).

3 See KSR, 550 US at 427 ("[T] he results of ordinary innovation are not the subject of exclusive rights under the patent laws. Were it otherwise patents might stifle, rather than promote, the progress of useful arts."); Bonito Boats, Inc v Thunder Craft Boats, Inc, 489 US 141, 146 (1989) ("[A] careful balance between the need to promote innovation and the recognition that imitation and refinement through imitation are both necessary to invention itself and the very lifeblood of a competitive economy.").

4 See Michael Abramowicz and John F. Duffy, The Inducement Standard of Patentability, 120 Yale L J 1590, 1594 (2011). 
Despite its centrality to patent law, nonobviousness has long been considered a particularly vague and unpredictable doctrine. Roughly a century after the Supreme Court first articulated the doctrine in Hotchkiss $v$ Greenwood, ${ }^{5}$ Judge Learned Hand famously lamented that nonobviousness was "as fugitive, impalpable, wayward, and vague a phantom as exists in the whole paraphernalia of legal concepts." 6 Today, the nonobviousness doctrine remains as vague a phantom as it was then. Judicial opinions have continued to struggle to articulate both what makes an invention significant (or nonobvious) and how to measure nonobviousness in specific cases. ${ }^{7}$

In this Article, we draw on a novel approach-network theory-to answer both the conceptual question (what is a nonobvious invention?) and the measurement question (how do we determine nonobviousness in specific cases?). We identify-and supply-a crucial missing piece in competing economic and psychological conceptualizations of patentability: an underlying theory of innovation. Building upon insights from network science, we model innovation as a process of search across knowledge networks and recombination of the knowledge obtained from this search process. ${ }^{8}$ As we elaborate more fully below, from a network theory perspective, the answer to the conceptual question is that nonobviousness should seek to incentivize those risky and costly distant searches and recombinations across knowledge networks that produce the most socially significant innovations. ${ }^{9}$ By emphasizing factors specific to the structure of innovation that law and economic analyses overlook-namely, the risks and costs of

\footnotetext{
552 US 248 (1851). The Supreme Court in Hotchkiss announced a third requirement for patentability in addition to the then-codified statutory requirements of novelty and utility. Id at 248, 267.

6 Harries v Air King Products Co, 183 F2d 158, 162 (2d Cir 1950). See also Gregory N. Mandel, Another Missed Opportunity: The Supreme Court's Failure to Define Nonobviousness or Combat Hindsight Bias in KSR v. Teleflex, 12 Lewis \& Clark L Rev 323, 324 (2008) (arguing, following the Court's opinion in KSR, that an exclusive focus on "the factual underpinnings that help inform non-obvious analysis ... has blinded many from the lapse that the quantum of ingenuity necessary to satisfy the non-obvious requirement has never been elaborated," and predicting that "[t]he failure to instruct on the legal question of nonobviousness means that non-obvious decisions will remain inconsistent and unpredictable"); Tun-Jen Chiang, A Cost-Benefit Approach to Patent Obviousness, 82 St John's L Rev 39, 54 (2008) (calling the nonobviousness doctrine a "plaything of the judiciary [that] mean[s] anything the judges cho[o]se to make it mean"), quoting Giles S. Rich, Why and How Section 103 Came to Be, 14 Fed Cir Bar J 181, 186 (2004).

7 See Part I.A.

8 See Part II.A.

9 See Parts II.B, II.C, and III.
} 
the search and recombination process-a network approach nuances current economic understandings of nonobviousness. ${ }^{10} \mathrm{Cru}$ cially, our network theory of innovation grounds the development of an empirical network measure of nonobviousness- the "network nonobviousness score" (NNOS). ${ }^{11}$ Because a network measure can provide a snapshot of the connections between technological areas at any given point in time, it simultaneously addresses two competing concerns in measuring nonobviousness: the need to correct for hindsight bias (which makes most inventions seem obvious after the fact) while accounting for forces that drive innovation without patent protection. ${ }^{12}$ Methodologically, this Article is the first to our knowledge to use network science to develop an algorithmic approach to legal decision-making. As is the case for any algorithm designed to guide legal decision-making, our measure raises questions about algorithmic bias. We take these concerns as an opportunity to further explore and illustrate how algorithmic design can influence doctrinal outcomes, and to engage with debates about algorithmic justice. ${ }^{13}$

At the root of nonobviousness's conceptual vagueness lies a series of judicial decisions stretching back to Hotchkiss that implicitly blend two theoretical approaches to conceptualizing nonobviousness-approaches that can lead to different prescriptive outcomes. ${ }^{14}$ The first approach, an economic one, conceptualizes nonobviousness as a policy lever to weed out those inventions that do not require the inducement of a patent because other incentives, such as market forces, provide sufficient motivation to innovate. This economic view emerged as early as 1883, when the Supreme Court in Atlantic Works $v$ Brady ${ }^{15}$ emphasized that a patent is unnecessary, and an invention is therefore obvious, when "[t]he process of development in manufactures creates a constant demand for new appliances, which the skill of ordinary head-workmen and engineers is generally adequate to devise, and which, indeed, are the natural and proper outgrowth of such development."16

Yet another perspective, a cognitive one, developed alongside this economic view and continues to influence nonobviousness decisions. Under a cognitive approach, the nonobviousness doctrine

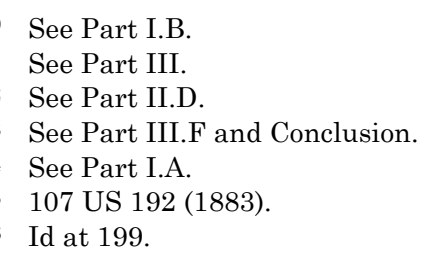


seeks to reward creative inventions that are outside the cognitive grasp of an "ordinary artisan." 17 This cognitive view is also present in the doctrine's earliest opinions, including Atlantic Works, in which the Court defined a nonobvious technical advance as one that evinced "the exercise of invention somewhat above ordinary mechanical or engineering skill." ${ }^{18}$ Although more recent decisions tend to emphasize an economic perspective, ${ }^{19}$ these two theoretical approaches continue to coexist. Indeed, the Supreme Court's most recent nonobviousness decision, KSR International Co $v$ Teleflex Inc, ${ }^{20}$ perpetuates this blended approach, implying that cognitive and economic rationales are one and the same. ${ }^{21}$ Yet there are key underlying normative differences between these two approaches. Some creative inventions may not need the economic inducement of a patent. Conversely, some uncreative but time- and labor-intensive inventions may not come to be absent such patent inducement. ${ }^{22}$

How we conceptualize nonobviousness has clear implications for how we measure it: Should nonobviousness rely on ascertaining how creative a particular invention is? Or should it instead focus on mapping the strength of market forces to determine whether it would have been achieved regardless of patent incentives? Measuring nonobviousness poses an additional challenge: that of guarding against hindsight bias while simultaneously giving enough weight to contextual factors that propel innovation. ${ }^{23}$ More specifically, whether through a cognitive or economic lens, ascertaining nonobviousness requires fact finders to "travel back

\footnotetext{
17 The ordinary artisan, or "person having ordinary skill in the art" (PHOSITA), is a construct in patent law, similar to the "reasonable person" in tort law that represents the "average" inventor. See for example Jonathan J. Darrow, The Neglected Dimension of Patent Law's PHOSITA Standard, 23 Harv J L \& Tech 227, 235 n 38 (2009). In Part III.E.2, we discuss how a network perspective provides a theoretical foundation for defining the background technical knowledge of a PHOSITA in a way that captures how that knowledge evolves over time-a task that patent law doctrine is currently ill-equipped to perform. A network perspective that views technological fields as evolving over time also raises important questions about how to define a PHOSITA's "primary field" of workquestions that are underresearched and undertheorized in patent law.

18 Atlantic Works, 107 US at 200.

19 See Part I.A.

20550 US 398 (2007).

21 See Part I.A.

22 See Part II.B.2.

23 "Hindsight bias" refers to people's subjective and unconscious tendency to incorrectly assign a high predictability to a past event based on their present knowledge that the event has, in fact, occurred. In other words, in hindsight, most inventions are likely to seem obvious. See Mandel, 12 Lewis \& Clark L Rev at 336-37 (cited in note 6).
} 
in time" to the moment of invention ${ }^{24}$ and, from this temporal vantage point, determine whether the invention "would have been obvious ... to a person having ordinary skill in the art." 25 This exercise-the reconstruction of the incentives and hurdles facing the inventor, and the mapping of the relevant universe of knowledge available to the inventor-entails a high risk of hindsight bias on the part of the fact finder, who has prior knowledge of the completed invention and the steps taken to create it. In short, most inventions will appear obvious in hindsight. ${ }^{26}$

These two ways of conceptualizing nonobviousness that emerged in doctrinal cases have their counterparts in the academic literature, reflected in two strands of theoretical writings: one emphasizing how to use insights from economics to define nonobviousness, the other emphasizing how to integrate psychological research on creativity to the nonobviousness inquiry. ${ }^{27} \mathrm{Un}$ der a law and economics view, patents should be granted only in cases of market failure - that is, when market forces alone are insufficient to bring about the invention. The goal of nonobviousness, then, is to identify those inventions that would not arise, or would be significantly delayed, but for the patent grant. Economic models of nonobviousness link such market failures to the uncertainty surrounding the outcome of a particular research path, as well as the costs of resolving such uncertainty. ${ }^{28}$ Therefore,

24 Depending on whether the invention falls under the 1952 Patent Act, 66 Stat 792, codified as amended in various sections of Title 35, or the Leahy-Smith America Invents Act (AIA), Pub L No 112-29, 125 Stat 284 (2011), codified in various sections of Title 35, the relevant time for assessing nonobviousness is "the time the invention was made" (under the 1952 Act), or the "filing date" (under the AIA).

2535 USC $\S 103$.

26 See, for example, Gregory N. Mandel, Patently Non-Obvious: Empirical Demonstration that the Hindsight Bias Renders Patent Decisions Irrational, 67 Ohio St L J 1391, 141114 (2006) (finding that "[e]x post knowledge of invention deeply affected participants' conclusions regarding whether an invention was non-obvious ex ante"); Gregory N. Mandel, Patently Non-Obvious II: Experimental Study on the Hindsight Issue Before the Supreme Court in KSR v. Teleflex, 9 Yale J L \& Tech 1, 18-20 (2006-2007) ("Participants who were not informed of the invention were substantially more likely to judge a solution non-obvious than participants who were informed what the invention was. This result held across both scenarios-whether there was a suggestion to combine prior art references or not.”).

27 See Part I.B.

28 See, for example, Robert P. Merges, Uncertainty and the Standard of Patentability, 7 High Tech L J 1, 47-55 (1992) (discussing how the nonobviousness standard could be used to incentivize uncertain and costly research); Glynn S. Lunney Jr, E-Obviousness, 7 Mich Telecomm \& Tech L Rev 363, 412-13 (2001) (arguing that the nonobviousness requirement can encourage individuals to invent uses that are most valuable to society by awarding patents only to inventions that were costly to create); Richard A. Posner and William M. Landes, The Economic Structure of Intellectual Property Law 304-05 (Harvard 2003) ("To the extent that the requirement of nonobviousness succeeds in preventing the 
uncertain and costly research typically requires the economic inducement of a patent to be produced at a socially optimal level. ${ }^{29}$ Proponents of a psychological (or cognitive) perspective view the core of patent law as concerned with providing inventors incentives to act creatively. ${ }^{30}$ Psychological theories of nonobviousness lead to a cognitive doctrinal framework aimed at identifying and rewarding creative inventions while avoiding hindsight bias that prevents observers from appreciating such creativity ex post. ${ }^{31}$

Both economic and psychological perspectives are limited in their ability to generate doctrinal prescriptions that can be easily applied by both the Patent and Trademark Office (PTO) and courts. ${ }^{32}$ Many of the contextual economic factors needed to assess the economic nonobviousness of an invention are quite hard, if not

patenting of inventions that would not cost a lot to discover and perfect, it limits patent races, which are more costly the greater the net expected gain from winning."); Michael J. Meurer and Katherine J. Strandburg, Patent Carrots and Sticks: A Model of Nonobviousness, 12 Lewis \& Clark L Rev 547, 570-74 (2008) (claiming that the nonobviousness standard should be a question of law so as to better incentivize inventors to pursue a more difficult research path with socially optimal rewards); Chiang, 82 St John's L Rev at 7276 (cited in note 6) (arguing that a cost-benefit approach to obviousness would better accelerate innovation); Abramowicz and Duffy, 120 Yale L J at 1597 (cited in note 4) (advocating that " $[\mathrm{u}]$ nder a rigorously enforced inducement standard, patents would cover only those innovations that otherwise would not be created or disclosed"). See also Part I.B.

29 See, for example, Merges, 7 High Tech L J at 47-55 (cited in note 28); Lunney, 7 Mich Telecomm \& Tech L Rev at 412-13 (cited in note 28); Meurer and Strandburg, 12 Lewis \& Clark L Rev at 570-74 (cited in note 28); Chiang, 82 St John's L Rev at 72-76 (cited in note 6).

30 See, for example, Jeanne C. Fromer, A Psychology of Intellectual Property, $104 \mathrm{Nw}$ U L Rev 1441, 1487 (2010) (arguing that the nonobviousness requirement emphasizes the value of creativity because "solutions that can be derived with at best a minimally creative process-possibly even absent certain steps, such as incubation-are not valuable"); Christopher Buccafusco, et al, Experimental Tests of Intellectual Property Laws' Creativity Thresholds, 92 Tex L Rev 1921, 1923-26 (2014) (evaluating whether different patentability thresholds would incentivize more creativity); R. Keith Sawyer, Creativity, Innovation, and Obviousness, 12 Lewis \& Clark L Rev 461, 481-85 (2008) (describing the research into hindsight bias and other forms of implicit bias that could guide courts in evaluating the obviousness of an invention); Colleen M. Seifert, Now Why Didn't I Think of That? The Cognitive Processes That Create the Obvious, 12 Lewis \& Clark L Rev 489, 494-507 (2008) (presenting the results of studies on problem-solving and creativity to conclude that understanding the nonobviousness of ideas requires a more extensive theory of human cognitive processes than the Supreme Court adopted in KSR); Steven M. Smith, Invisible Assumptions and the Unintentional Use of Knowledge and Experiences in Creative Cognition, 12 Lewis \& Clark L Rev 509, 516-23, 523-25 (2008) (analyzing research on innovation and the creative process to suggest a guide for nonobviousness in patent law); Janet Davidson and Nicole Greenberg, Psychologists' Views on Nonobviousness: Are They Obvious?, 12 Lewis \& Clark L Rev 527, 540-43 (2008) (suggesting that patent lawyers and cognitive psychologists form a collaborative web to help resolve patent issues surrounding nonobviousness).

31 See Part I.B.

32 Id. 
impossible, for the PTO to evaluate. ${ }^{33}$ For instance, assessing surges of market demand for a particular invention that would suggest the invention is obvious is outside the expertise of patent examiners. The same is true of assessing whether an exogenous technological advance took place around the date of invention. Such an assessment requires the type of meta-analysis of innovation trends that neither the PTO nor the courts are equipped to carry out. For their part, psychological theorists have also struggled to translate their conceptual insights into easily applicable doctrinal frameworks. First, although psychological theory emphasizes the pervasiveness of hindsight bias, it provides no clear way to debias observers. To the contrary, most experiments on hindsight bias show it to be persistent and resistant to debiasing interventions. ${ }^{34}$ Second, creativity exists on a continuum, ${ }^{35}$ and psychological theories cannot answer the important question of where to draw the line between obvious and nonobvious inventions or even how to measure where an invention might be on that creativity continuum.

This Article makes three key contributions: First, to theoretical debates surrounding how to conceptualize nonobviousness. Second, to doctrinal debates surrounding how to best measure nonobviousness. Finally, to broader concerns in the legal academy about the use and misuse of legal algorithms. At the theoretical level, we draw upon a rich body of literature that approaches innovation from a network perspective. By modeling innovation as the result of recombinant search across information and social networks-that is, as the product of seeking out information and recombining it in new ways-networked innovation research has both enriched our understanding of how significant innovation occurs, as well as our ability to predict and measure it. From a

33 The Court in Graham v John Deere Co of Kansas City, 383 US 1 (1966), made clear that "the primary responsibility for sifting out unpatentable material lies in the Patent Office," thus highlighting the importance of developing a nonobviousness test that can be applied both by the PTO and the courts. Id at 18 .

34 See, for example, Mandel, 67 Ohio St L J at 1400-03 (cited in note 26) (collecting sources that explain how "[t]he hindsight bias has proven remarkably unyielding to varied efforts to ameliorate its impact"); Davidson and Greenberg, 12 Lewis \& Clark L Rev at 539 (cited in note 30) ("Hindsight bias is poisonous for the nonobviousness requirement in patent law. Even though the Supreme Court thinks it sufficient for patent examiners and courts simply to be aware of, and cautious about, hindsight bias, research presents a compelling case that this bias is impervious to change.").

35 See, for example, Davidson and Greenberg, 12 Lewis \& Clark L Rev at 541-42 (cited in note 30) (challenging the contention that an invention is obvious if someone of average skill in the arts could identify the invention via normal processes because "psychological models of creativity propose that individuals use the same mental processes for both routine and non-routine problem solving"). 
network perspective, particular innovations can be understood as the product of two different types of search and recombination strategies-often characterized as "global" or "local" searches. These two types of searches reveal two different underlying innovation structures that provide strong signals about how risky and costly a particular innovation is, as well as how likely it is to provide a large social benefit. All else being equal, global searches and recombinations are costlier, riskier, and more socially significant-and therefore less economically obvious - than their local counterparts. To succeed, global searches and recombinations typically require the bridging of large cognitive distances between two or more technological communities. This type of bridging entails the costly assembly of teams with multiple kinds of expertise and the development of tools to bridge those large cognitive distances between technological domains. In contrast, research involving local search and recombination is likely to involve welltrodden technical areas in which routines and tools for answering typical domain questions have evolved. ${ }^{36}$ Because all else is almost never equal, however, we also analyze situations when global searches may nevertheless result in an economically obvious invention (for example, when the technological distances we employ in our empirical measure do not correspond well with cognitive distances), and when local searches may nonetheless require the inducement of a patent (such as those in which preexisting knowledge elements provide only a starting point for intensive and costly research).

Our theoretical analysis of the nonobviousness requirement leads to several important refinements to the predominant economic view, which we largely adopt as the best reading of the patent statute. First, we note that the market forces emphasized by economic views (demand surges and exogenous technological developments) fail to capture important structural determinants to innovation. ${ }^{37}$ Our theory pinpoints innovation-specific factorsthe technological and cognitive distance between the knowledge domains recombined in a given invention-that deeply influence the invention's economic risk and cost, and therefore its economic nonobviousness. ${ }^{38}$ Second, we show how some psychological

36 See Parts II.A-B.

37 For an in-depth analysis of the structural and social barriers leading to innovation failures, see generally Laura G. Pedraza-Fariña, The Social Origins of Innovation Failures, 70 SMU L Rev 377 (2017).

38 See Part II.B. 
measures of creativity - those that see increased creativity as resulting from the combination of cognitively distant knowledge domains-are directly correlated with market failures. A network perspective thus provides a way to reinterpret seemingly irreconcilable judicial opinions that blend psychological and economic perspectives by reframing some psychological measures of creativity as proxies for economic nonobviousness. ${ }^{39}$

Moving from theory to doctrine, network science allows us to develop an objective network measure of nonobviousness that recognizes the dynamic nature of innovation. Through our algorithmic network nonobviousness score (NNOS), our network approach can quantify an important feature that helps distinguish obvious from nonobvious inventions: the technological distance that an invention traverses in the process of recombining knowledge inputs. To develop our NNOS, we harness the vast yet largely untapped trove of data from patent records dating back to 1836. This data contains the classification records according to technology class for every patent granted since 1836,40 a total of over thirty-nine million classification events. We use these classification records to assemble a network representation of the different areas of technical knowledge used in inventions. This network can then help show the structure of the knowledge recombinations that underlie any given patent.

An example is helpful to illustrate how we calculate an invention's NNOS. Let's begin with a likely familiar invention: the development of a machine-learning thermostat (a thermostat that is able to learn over time to maintain energy efficiency). ${ }^{41}$ The PTO assigned this invention to the following three technological categories: (1) Air conditioning/ventilation systems; (2) Systems for controlling nonelectric variables; and (3) Transmission of digital information. To calculate the NNOS for this invention, first, we calculate the pairwise probability (between each combination

39 See Part II.C.

$40 \quad 1836$ is the earliest year for which we have reliable patent data because a fire at the patent office destroyed earlier patenting records. See Alan C. Marco, et al, The USPTO Historical Patent Data Files: Two Centuries of Invention *12 (unpublished USPTO Economic Working Paper No 2015-1, June 2015), archived at https://perma.cc/6BRZ -Y72R. The data used in our analyses below draws on all of this patenting data for all utility patents granted up to the end of 2016. See Part III.B.

41 The patent relating to this example is Yoky Matsuoka, et al, HVAC schedule establishment in an intelligent, network-connected thermostat, US Patent No 9,256,230 (filed Feb 27, 2014), archived at https://perma.cc/7JHQ-DL85. For a more comprehensive explanation of the NNOS calculation, with specific reference to this particular invention, see Part III.C. 
of two categories) that such combination appeared in all inventions that came before the invention at issue. In other words, we ask the question: In the universe of all prior inventions before the date of the present invention, how frequently did a patent show a combination of technologies (1) and (2); (1) and (3); and (2) and (3)? Second, we choose the pair of technology areas that represent the longest knowledge distance between any two technology areas (and therefore the lowest recombination probability). We take this recombination probability as an invention's NNOS-in other words, the recombination probability of the most distant pair of technology classes, representing the biggest recombination leap contained in the invention. In this particular example, drawn from a real-life patent, the recombination probability between (1) and (2) is 0.03690 . The recombination probability between (1) and (3) is 0.01116 . And the recombination probability between (2) and (3) is 0.00666. ${ }^{42}$ Therefore, the NNOS for this invention is 0.00666 .

These probabilities also tell a story about the technological trajectory of this invention. The fact that technology areas (1) and (2) display the highest recombination frequency of all three combinations tells us that, at the time of the invention, inventions that brought together air conditioning/ventilation technology and systems for coordinating nonelectrical variables were relatively commonplace. That these two occur together relatively often is unsurprising, as temperature is one potential nonelectric variable. In contrast, inventions that combined technology area (3) (transmission of digital information) with either technology areas (1) or (2) were relatively rare. This indicates that, at the time of the invention, very few inventions combined the digital transmission of information with mechanical air conditioning/ventilation systems and systems of controlling nonelectric variables. The least frequent combination-between systems for controlling nonelectric variables and transmission of digital information-indicates that the invention at issue was a pioneer in developing thermostats that are capable of being programmed and modified remotely through digital signals. In turn, this suggests that the

42 Note that for each pair there are two recombination frequencies: for example, the frequency with which a patent containing category (1) also contains category (2), and the frequency with which a patent containing category (2) also contains category (1). We choose the highest frequency between any given pair as the representative frequency for the purpose of NNOS calculation, choosing the technological community with the highest likelihood of making a particular recombination leap as our reference community. See Part III.C. 
thermostat's development was the result of global search and recombination processes, and thus required the economically risky recombination of cognitively distant knowledge. ${ }^{43}$

Because the distance between technology classes and the background knowledge of inventors changes over time, our measure allows us to "travel back in time" to identify combinations that were atypical when first created, but may now have become commonplace, as is the case with the thermostat example abovethus avoiding hindsight bias. ${ }^{44}$ Although network nonobviousness scores, like creativity, also exist on a continuum, we can measure where a particular invention falls within that continuum-allowing for more precise comparisons between inventions.

To illustrate how our empirical network nonobviousness measure can help guide decision-making, we apply it to litigated cases. ${ }^{45}$ Our measure identifies several cases that have been incorrectly decided under a network theory of patentability, while also providing empirical support for many other Federal Circuit nonobviousness decisions. 46 We propose a doctrinal framework that incorporates the NNOS as an initial threshold test to sort patents into local and global types and to guide further analysis based on the different innovation dynamics underlying these two innovation types. ${ }^{47}$

Finally, our Article is the first to our knowledge to employ a network methodology to design a prescriptive, doctrinal legal test-as opposed to a descriptive or predictive analysis. ${ }^{48}$ Network science has been one of the most important methodological developments in both the natural and social sciences in recent decades. ${ }^{49}$ Network science methodology has slowly made its way into empirical legal studies. Most empirical legal studies applying this methodology, however, have been descriptive or predictive. ${ }^{50}$ For example, in patent law, scholars have used network science to

43 See Part III.C.

44 See Part II.D.

45 See Part III.D.

46 See id

47 See Part III.E.

48 In law, scholars have begun applying networks in a variety of ways but most of them have been descriptive. See, for example, Ryan Whalen, Legal Networks: The Promises and Challenges of Legal Network Analysis, 2016 Mich St L Rev 539, 556, 559-65.

49 For a description of the varied and powerful uses of network science, see David Easley and Jon Kleinberg, Networks, Crowds, and Markets: Reasoning About a Highly Connected World 7-17 (Cambridge 2010).

50 See, for example, Whalen, 2016 Mich St L Rev at 556 (cited in note 48); text accompanying notes 201-05. 
predict the emergence of new technologies, ${ }^{51}$ or as a tool in patent valuation. ${ }^{52}$ Previous studies on the importance of incentivizing boundary-crossing innovations, including work by Professor Michal Shur-Ofry ${ }^{53}$ and some of our prior work, ${ }^{54}$ have theorized on the desirability of using patent data to identify breakthrough interdisciplinary innovations, but have not in fact developed or validated such a metric. In this Article, we provide an example of how network science can be used to create measures or algorithms that can help guide normative decision-making. We also explore the importance of algorithmic design choices, providing insight into challenges facing the legal system as computationally enabled decision-making tools begin to proliferate.

This Article proceeds by first examining, in Part I, the doctrinal and theoretical foundations of the nonobviousness requirement. We focus on two concerns that have guided the development of nonobviousness doctrine and theory: the friction between cognitive and economic conceptualizations of nonobviousness, and the difficulties in crafting a doctrinal test that both protects against hindsight bias while giving due weight to market forces that spur innovation without patent protection. In Part II, we then introduce a network perspective on innovation, and explore how it can both help us understand what it means for something to be obvious, and how that understanding can be reconciled with previous attempts to theorize nonobviousness from an economic and psychological perspective. In Part III, we use our network

51 See, for example, Péter Érdi, et al, Prediction of Emerging Technologies Based on Analysis of the US Patent Citation Network, 95 Scientometrics 225, 231-34 (2013) (developing a methodology to predict the emergence of new technological fields through the US patent citation network); Katherine J. Strandburg, et al, Law and the Science of Networks: An Overview and an Application to the "Patent Explosion", 21 Berkeley Tech L J 1293, 1329-39 (2006) (studying the evolution of the patent citation network, and arguing that patents-at the time of the study-were increasingly being granted for trivial improvements); Katherine J. Strandburg, et al, Patent Citation Networks Revisited: Signs of a Twenty-First Century Change?, 87 NC L Rev 1657, 1671-79 (2009) (continuing the prior study of the evolution of the patent citation network to find that the trend toward triviality had leveled off).

52 See, for example, Andrew W. Torrance and Jevin D. West, All Patents Great and Small: A Big Data Network Approach to Valuation, 20 Va J L \& Tech 466, 486-98 (2017).

53 Michal Shur-Ofry, Connect the Dots: Patents and Interdisciplinarity, 51 U Mich J L Ref 55, 76-84 (2017) (proposing that patent law should reward "technologies that connect disparate dots and distinguish them from more ordinary combinations").

54 See Laura G. Pedraza-Fariña, Patent Law and the Sociology of Innovation, 2013 Wis L Rev 813, 861 (proposing that the nonobviousness doctrine should incentivize boundary-crossing innovation); Pedraza-Fariña, 70 SMU L Rev at 437 (cited in note 37) (arguing that "patent applicants before the PTO (or litigants before a court) could also introduce evidence that a particular patent employed a rare combination of technological subclasses as evidence of non-obviousness"). 
theory of innovation to motivate a network measure of nonobviousness (what we term the network nonobviousness score, or NNOS). We apply the NNOS to four case examples, demonstrating that an empirical measure of nonobviousness that is grounded in network theory can provide objective insight into the patentability analysis that both leverages the vast stores of innovation data produced by the patent system and is also robust to hindsight bias. Finally, we illustrate alternative network measures of nonobviousness, and discuss how these network measures can be refined and integrated into the current doctrinal framework for nonobviousness. In our Conclusion, we engage with debates around algorithmic bias and the perils of black box algorithms by discussing specific algorithmic design choices embedded in the NNOS.

\section{A BRIEF History OF NONOBVIOUsness THEORY AND DOCTRINE}

In this Part, we reconstruct the history of nonobviousness theory and doctrine by focusing on two pivotal controversies that have shaped the direction of nonobviousness jurisprudence. The first controversy concerns the clash between economic and cognitive approaches to the conceptual question: What does it mean for an invention to be nonobvious? We trace the development of judicial decisions, focusing on their gradual transition from a cognitive to an economic approach. Despite a growing trend to view nonobviousness from an economic perspective, modern nonobviousness decisions are best described as hybrids: relying on a blend of economic and cognitive justifications of nonobviousness. The second controversy concerns how to best measure nonobviousness. More specifically, it concerns how to balance two competing concerns: counteracting hindsight bias-or the tendency to assign an incorrectly high probability of success to inventions when evaluated ex post, either during patent examination or litigationwhile preserving the flexibility that would allow fact finders to consider how market and other forces incentivize innovation without patent protection. 


\section{A. Doctrinal Evolution: From Cognitive to Economic} Approaches

The Supreme Court first articulated what would later become codified as the nonobviousness requirement in Hotchkiss $v$ Greenwood. ${ }^{55}$ The invention at issue in Hotchkiss-a clay or porcelain doorknob-met the two statutory requirements for patentability at that time, novelty and utility. ${ }^{56}$ The invention was, however, a substitution of a well-known doorknob material (wood or metal) for another (clay or porcelain). ${ }^{57}$ Finding such substitution to be "the work of the skillful mechanic, not that of the inventor," 58 the Court both refused to grant a patent on that particular invention and announced a new rule that proved to be deeply influential: "[U]nless more ingenuity and skill . . . were required . . . than were possessed by an ordinary mechanic acquainted with the business," the patent was void. ${ }^{59}$ This new rule in fact added a third requirement of "a degree of skill and ingenuity" to the two existing statutory requirements that an invention be both useful and new. ${ }^{60}$

The opinion's short analysis of this new patentability requirement, however, left the door open for two possible-and divergent-interpretations. Does patentability require a showing of subjective creativity or "creative genius," compared to the lower level of creativity possessed by an "ordinary mechanic"? Or is the inquiry an objective search for substantial advances in the art? And, if the inquiry is objective, does proving a substantial advance require a showing of objective insight or creativity (a cognitive interpretation) or is the inquiry a search for advances in the art that require the (economic) inducement of a patent? ${ }^{61}$

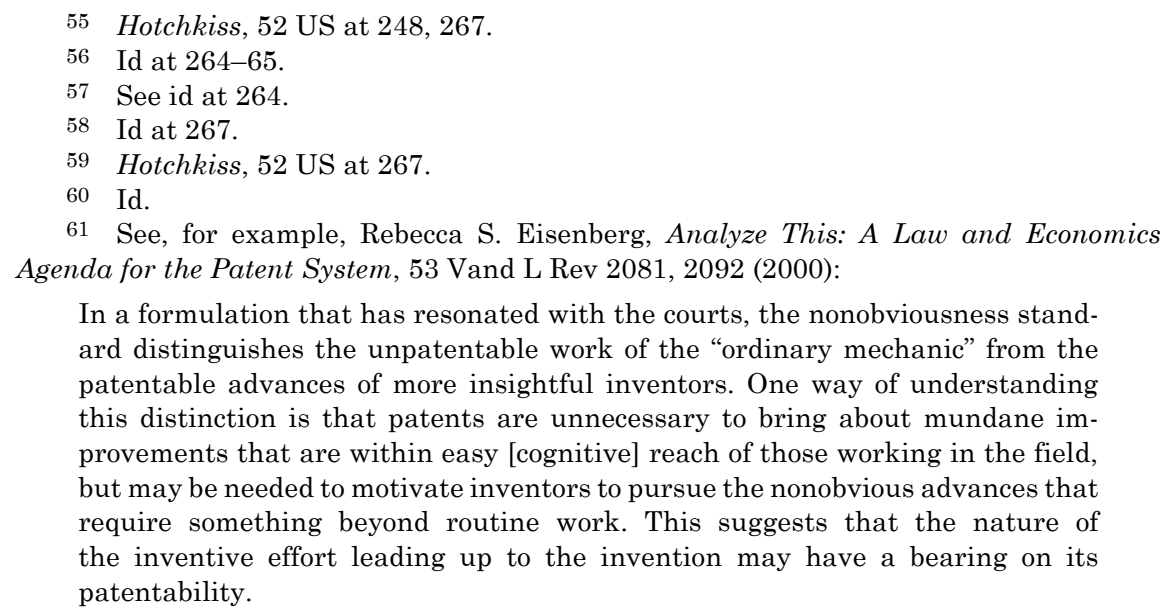

In a formulation that has resonated with the courts, the nonobviousness standard distinguishes the unpatentable work of the "ordinary mechanic" from the patentable advances of more insightful inventors. One way of understanding this distinction is that patents are unnecessary to bring about mundane improvements that are within easy [cognitive] reach of those working in the field, but may be needed to motivate inventors to pursue the nonobvious advances that require something beyond routine work. This suggests that the nature of the inventive effort leading up to the invention may have a bearing on its patentability. 
Some decisions following Hotchkiss embraced a subjective inquiry: focusing on the cognitive processes taking place in the mind of the inventor and looking for a "flash of creative genius" to merit patent protection. ${ }^{62}$ In the most notable decision embodying the subjective approach, Cuno Engineering Corp v Automatic Devices Corp ${ }^{63}$ the Court denied a patent on the first cordless automobile cigarette lighter because the new device, in the words of Justice William O. Douglas, did not "reveal the flash of creative genius," but rather reflected "merely the skill of the calling." 64 Under Cuno's subjective standard, the inventor's own mental processes in devising the invention played an outsized role. The subjective standard thus privileged invention stories that involved unexplainable "flashes of insight," or those proverbial "Eureka!" moments that occur when the inventor least expects them. Cuno's subjective standard was widely criticized as inconsistent with patent law's utilitarian justification that focuses instead on achieving social benefits through the promotion of innovation, regardless of whether such innovation came about through painstaking research or a moment of inspired insight. ${ }^{65}$

Although Cuno appeared to adopt a subjective perspective, other decisions following Hotchkiss had taken an objective approach, requiring that the invention represent a significant enough technical improvement over the existing art. For example, in Atlantic Works, an early Supreme Court case that came on the heels of the Hotchkiss decision, the Court emphasized how the utilitarian underpinnings of patent law required that patents only "reward those who make some [objectively] substantial discovery or invention, which adds to our knowledge and makes a step in advance in the useful arts."66 Atlantic Works also stands out as one of the earliest cases to emphasize what we would now

See also Abramowicz and Duffy, 120 Yale L J at 1604-12 (cited in note 4) (arguing that both "courts and commentators have tended to assume, implicitly or explicitly, that the doctrine focuses on the degree of cognitive difficulty in conceiving the invention" but emphasizing that "economic factors that make the process of developing something new more or less difficult" should take center stage in nonobviousness determinations).

62 See Cuno Engineering Corp v Automatic Devices Corp, 314 US 84, 91 (1941) (holding that a patentable invention "must reveal the flash of creative genius, not merely the skill of the calling").

63314 US 84 (1941).

64 Id at 91.

65 See, for example, Aram Boyajian, The Flash of Creative Genius: An Alternative Interpretation, $25 \mathrm{~J}$ Patent Office Society 776, 776-78 (1943) (summarizing contemporary criticisms of the Cuno decision).

66 Atlantic Works, 107 US at 200. 
consider an economic view of nonobviousness: the idea that market forces create a baseline demand for routine, spontaneous improvements that require no patent inducement. ${ }^{67}$ Atlantic Works, like many other decisions that followed, however, answered the conceptual question-what counts as a substantial advance?with a blended economic and objective cognitive test. Under such a blended approach, a substantial advance was one that both evinced "the exercise of invention, somewhat above ordinary mechanical or engineering skill"68 (a cognitive test), and that would not be the "natural and proper outgrowth" of market demand forces (an economic test). ${ }^{69}$ Atlantic Works's cognitive test was objective (in contraposition to Cuno's subjective test) because it sought to find out whether, in the eyes of an expert in the field, the advance at issue demonstrated a level of objective skill or creativity beyond the field's "average" skill level. In this Article, when we discuss the clash between economic and cognitive approaches, we refer to this objective version of the cognitive test. ${ }^{70}$

One way to interpret the blending of cognitive and economic rationales is to think of objective cognitive tests as "proxies" or shortcuts for identifying inventions that require the economic inducement of a patent. As we argue in more detail in Part I.B, this interpretation is most consistent with the utilitarian rationale for granting patents embedded in the Constitution. ${ }^{71}$ It is also justified under the model of innovation that we develop in Part II, but only for a specific type of innovation (boundary-crossing innovation). What is problematic about Atlantic Works and the many decisions that follow that continue to use this blended approach, however, is that this "proxy" rationale is never made explicit. Rather, the cognitive and economic rationales are implicitly taken to be one and the same. Yet, as advances in the fields of economics and psychology make clear, there are key underlying normative differences between these two approaches that can lead to different prescriptive outcomes. A cognitive (or psychological) approach

67 Id at 199-200 ("It was never the object of those laws to grant a monopoly for every trifling device, every shadow of a shade of an idea, which would naturally and spontaneously occur to any skilled mechanic or operator in the ordinary progress of manufactures.”).

68 Id at 200.

69 Id at 199.

70 Other authors have referred to what we call the economic approach as a "contextual approach," and to what we call the cognitive approach as a "technological" approach. Meurer and Strandburg, 12 Lewis \& Clark L Rev at 571-72 (cited in note 28).

71 See US Const Art I, § 8, cl 8 ("[The Congress shall have power] [t]o promote the Progress of Science and useful Arts, by securing for limited Times to Authors and Inventors the exclusive Right to their respective Writings and Discoveries.”). 
asks: Could an average practitioner think of (or predict) this outcome ex ante? Is this innovation creative? In contrast, an economic approach asks: Are market incentives sufficient to bring about this innovation? Some creative inventions may not need the economic inducement of a patent. Conversely, some uncreative but time- and labor-intensive inventions may not come to be absent such patent inducement. In short, a cognitive test will not always serve as a good proxy for an economic inducement standard.

The doctrinal debates that emerged following Hotchkiss motivated congressional action to codify the nonobviousness standard in the 1952 Patent Act. ${ }^{72}$ Under this Act, any new and useful invention would nonetheless be deemed unpatentable if it "would have been obvious at the time the invention was made to a person having ordinary skill in the art to which said subject matter pertains." 73 The 1952 Act eliminated subjective tests of patentability, emphasizing that "[p]atentability shall not be negatived by the manner in which the invention was made." ${ }_{4}$

Following the passage of the 1952 Patent Act, the Supreme Court addressed the nonobviousness standard's underlying theoretical foundations at two crucial time points: in 1966, when the Court in Graham v John Deere Co of Kansas City ${ }^{75}$ addressed the nonobviousness requirement following the passage of the 1952 Patent Act, ${ }^{76}$ and in 2007, when the Court in KSR reviewed the Federal Circuit's interpretation of its prior decisions on nonobviousness. ${ }^{77}$ An analysis of these two decisions reveals a Court that

\footnotetext{
7266 Stat 792 , codified as amended in various sections of Title 35. See Graham, 383 US at 15 (finding that the 1952 Patent Act was passed to have a "stabilizing effect" on the interpretations of the nonobviousness requirement), quoting HR Rep 1293, 82d Cong, 2d Sess 7 (1952). For examples of the contemporary debate and disagreement surrounding obviousness, see Radiator Specialty Co v Buhot, 39 F2d 373, 376 (3d Cir 1930) ("It is with the inventive concept, the thing achieved, not with the manner of its achievement or the quality of the mind which gave it birth, that the patent law concerns itself."); Chicago Steel Foundry Co v Burnside Steel Foundry Co, 132 F2d 812, 817 (7th Cir 1943) ("The test of a 'flash of genius' should be rejected."); John A. Dienner, The "Flash of Genius" Concept: Is It a Sound Standard?, 195 J Commerce 39, 40 (Mar 11, 1943) ("The Supreme Court was asked ... to reconsider and abandon the '[flash of genius] doctrine' but declined to do so. Since the judiciary appears thereby to have invaded the exclusive province of Congress, a legislative declaration of policy by the Congress appears to be in order, and should be sought.").

7335 USC $\S 103$.

$74 \quad 35$ USC $§ 103$.

75383 US 1 (1966).

76 Id at $12-15$.

77 KSR, 550 US at 415-18. In the intervening years, the Court also addressed nonobviousness in two additional decisions: Anderson's-Black Rock, Inc v Pavement Salvage Co, 396 US 57, 62-63 (1969) (finding that an invention was not patentable because "those
} 
has more explicitly endorsed an economic view of nonobviousness while still consistently - and likely also inadvertently-continuing to blend cognitive and economic justifications.

The Court in Graham sought to clarify the relationship between the nonobviousness requirement as codified in the 1952 Patent Act and the line of cases following Hotchkiss. ${ }^{78}$ Graham rejected the subjective interpretation of nonobviousness arising from Cuno, that would focus on the mental steps taken to achieve the invention. ${ }^{79}$ But the Court justified its objective formulation using both cognitive and economic perspectives. Thus, the Court clarified the holding of Cuno as requiring that "the subject matter sought to be patented ... be beyond the skill of the calling"-an objective cognitive perspective akin to that of Atlantic Works. ${ }^{80} \mathrm{On}$ the other hand, the Court famously defined the ultimate goal of the nonobviousness inquiry in clear economic terms: nonobviousness serves as a "means of weeding out those inventions which would not be disclosed or devised but for the inducement of a patent." 81

Forty-one years later, in $K S R$, the Court returned to the topic of nonobviousness in a much-changed patent landscape. In the years since Graham, the system of patent law had undergone a seismic structural change: no longer the province of fractured circuit courts, all patent appeals had since 1982 been concentrated into a single circuit-the Federal Circuit. ${ }^{82}$ This concentration brought with it a revolution in patent jurisprudence. The Federal Circuit, taking seriously its mandate to "reduce the widespread lack of uniformity and uncertainty of legal doctrine that exists in

skilled in the art [would conclude that] the use of the old elements in combination was not an invention by the obvious-nonobvious standard") and Sakraida v Ag Pro, Inc, 425 US 273, 280-82 (1976) (invalidating a patent because "[e]xploitation of . . gravity adds nothing to the sum of useful knowledge where there is no change in the respective functions of the elements of the combination; this particular use of the assembly of old elements would be obvious to any person skilled in the art of mechanical application"). But these decisions have played a less prominent role in the nonobviousness canon.

78 Graham, 383 US at 14.

79 Id at $15-17$.

80 Id at $15 \mathrm{n}$ 7. The Court also cited with approval a reformulation of the nonobviousness doctrine that would expressly link the nonobviousness standard to an inventionfocused creativity threshold, by explaining nonobviousness as requiring that "the device ... reveal the "flash of [objectively] creative genius." Id.

81 Id at 11.

82 Federal Courts Improvement Act of 1982, Pub L No 97-164, 96 Stat 25, codified as amended in various sections of Title 28. 
the administration of patent law," 83 set out to actively reshape existing patent law doctrines. With its heightened status as the "gatekeeper" of the patent system, the nonobviousness doctrine was a prime target of such doctrinal reshaping. Much of the Federal Circuit's new jurisprudence on nonobviousness, however, concerned not so much the definition of nonobviousness as its measurement. The Federal Circuit was particularly concerned with achieving uniformity and predictability in nonobviousness decisions by eliminating hindsight bias, which was thought to prejudice fact finders toward finding most inventions obvious. ${ }^{84}$ To address hindsight bias, the Federal Circuit developed a rigid rule, the teaching-suggestion-or-motivation (TSM) test, directed at reducing fact finder discretion. ${ }^{85}$ It was to address whether this rigid rule was consistent with the Graham framework that the Supreme Court returned to the nonobviousness doctrine in KSR. ${ }^{86}$

The invention in $K S R$ concerned an adjustable automotive pedal system with a modular electric sensor (rather than a mechanical sensor). ${ }^{87}$ The key nonobviousness question was whether it would have been obvious to a person having ordinary skill in the art to modify existing adjustable pedals with an electronic sensor, given the exogenous development of electronic sensor technology. ${ }^{88}$ In rejecting the Federal Circuit's rigid TSM test, and finding the invention obvious, the Court employed a decidedly economic view of nonobviousness. Specifically, the Court focused on the impact of "design incentives and other market forces" in

83 Court of Appeals for the Federal Circuit Act of 1981, HR Rep 97-312, 97th Cong, 1 st Sess 23.

84 See, for example, Polaris Industries, Inc v Arctic Cat, Inc, 882 F3d 1056, 1068 (Fed Cir 2018) (“'[T]he prejudice of hindsight bias' often overlooks that the 'genius of invention is often a combination of known elements which in hindsight seems preordained."), quoting Power Integrations, Inc v Fairchild Semiconductor International, Inc, 711 F3d 1348, 1368 (Fed Cir 2013).

85 Under the TSM test, courts asked whether the prior art taught, suggested, or motivated the combination. If it did, then the invention was obvious. For a more detailed explanation, see the text accompanying notes 107-12.

86 The question presented was:

Whether the Federal Circuit has erred in holding that a claimed invention cannot be held "obvious," and thus unpatentable under 35 USC $§ 103(a)$, in the absence of some proven "teaching, suggestion, or motivation' that would have led a person of ordinary skill in the art to combine the relevant prior art teachings in the manner claimed."

Petition for a Writ of Certiorari, KSR International Co v Teleflex Inc, No 04-1350, *i (US filed Apr 6, 2015) (available on Westlaw at 2005 WL 835463).

$87 K S R, 550$ US at 406, 409-11.

88 Id at 424-25 ("The proper question to have asked was whether a pedal designer of ordinary skill, facing the wide range of needs created by developments in the field of endeavor, would have seen a benefit to upgrading [the pedal system] with a sensor."). 
prompting innovation without the need for a patent incentive. ${ }^{89}$ The Court largely rests its holding on a succinct economic justification for the doctrine: "There then existed a marketplace that created a strong incentive to convert mechanical pedals to electronic pedals, and the prior art taught a number of methods for achieving this advance." ${ }^{0}$ In other words, an invention is nonobvious only when the market fails to incentivize that particular invention.

Despite its strong economic underpinnings, the Court in $K S R$ continued to blend economic and cognitive perspectives. For example, the opinion used cognitive or psychological concepts to contrast inventions displaying "ordinary skill" and "ordinary creativity," which are undeserving of patent protection, with those that result from "real innovation," which should be granted patent protection. ${ }^{91}$ The opinion's concluding paragraph also suggests a cognitive rationale for nonobviousness: "KSR provided convincing evidence that mounting a modular sensor on a fixed pivot point of the Asano pedal was a design step well within the grasp of a person of ordinary skill in the relevant art."92 In other words, an ordinary artisan of "ordinary creativity" 93 could cognitively imagine the invention at the outset.

In summary, the doctrinal answer to the conceptual question-what makes an invention nonobvious?-is a blend of cognitive and economic rationales, with an economic understanding of nonobviousness becoming more prominent in the most recent Supreme Court decisions. How we define nonobviousness has clear implications for how we measure it: Should nonobviousness rely on ascertaining how creative a particular invention is? Or should it instead focus on mapping the strength of existing market and social forces at the time of the invention to determine whether it would have been achieved regardless of patent incentives? We next turn to explore in more detail the judicial answer to this measurement question: the specific doctrinal framework that has evolved to determine whether an invention clears the nonobviousness threshold. We pay particular attention to an important disagreement between the Federal Circuit and the Supreme Court regarding how to simultaneously correct for hindsight bias while

\footnotetext{
89 Id at 417.

90 Id at 424.

91 KSR, 550 US at 419-20.

92 Id at 427 (emphasis added).

93 Id at 421.
} 
taking into account market forces that foster innovation without patent protection.

The Court in Graham laid out the basic tripartite doctrinal framework for nonobviousness that we still use today. First, the scope and content of the prior art must be determined. ${ }^{94}$ The "scope and content" inquiry requires identifying the collection of all publicly available knowledge that an ordinary mechanic-or "person having ordinary skill in the art" (PHOSITA) - would rationally consult when attempting to carry out her invention. ${ }^{95} \mathrm{Un}$ like the novelty inquiry, in which every single piece of publicly available knowledge is considered "prior art," 96 the nonobviousness inquiry recognizes that inventors are only likely able to rely upon and recombine knowledge within their specific fields of endeavor, or in fields that are rationally related to the problem they are trying to solve. ${ }^{97}$ Therefore, prior art for nonobviousness purposes is cabined to such "analogous" prior art.98 Second, the differences between this prior art and the claimed invention must be ascertained in light of, third, the level of ordinary skill in the pertinent art. 99

In essence, the Graham framework calls on fact finders to put themselves in the shoes of a PHOSITA and, from this perspective, gather all relevant publicly available information that a PHOSITA would reasonably consult to solve her problem, and determine whether the differences between the invention at issue and the prior art knowledge are such that the invention reflects a sufficiently inventive, non-trivial step to merit patent protection. The Court in Graham also emphasized that "secondary considerations" of nonobviousness, such as "commercial success, long felt but unsolved needs, [and] failure of others," "may have relevancy"

\footnotetext{
94 Graham, 383 US at 17.

95 See, for example, In re Winslow, 365 F2d 1017, 1020 (CCPA 1966) ("We think the proper way to apply the 103 obviousness test to a case like this is to first picture the inventor as working in his shop with the prior art references-which he is presumed to know-hanging on the walls around him.").

96 See, for example, In re Robertson, 169 F3d 743, 745 (Fed Cir 1999) ("Anticipation under 35 USC $\S 102(\mathrm{e})$ requires that "each and every element as set forth in the claim is found, either expressly or inherently described, in a single prior art reference."'), quoting Verdegaal Bros, Inc v Union Oil Co, 814 F2d 628, 631 (Fed Cir 1987).

97 In re Bigio, 381 F3d 1320, 1325 (Fed Cir 2004).

98 Two criteria are relevant in determining whether prior art is analogous: "(1) whether the art is from the same field of endeavor, regardless of the problem addressed and, (2) if the reference is not within the field of the inventor's endeavor, whether the reference still is reasonably pertinent to the particular problem with which the inventor is involved." Id at 1325.

99 Graham, 383 US at 17.
} 
as "indicia of obviousness." 100 In more recent caselaw, this list of secondary considerations-which the Federal Circuit has also termed "objective indicia of nonobviousness"-has expanded ${ }^{101}$ and taken a crucial role as a mandatory fourth prong in Graham's tripartite framework. ${ }^{102}$

Although Graham firmly rejects a subjective approach to nonobviousness that would focus on the mental qualities of the inventor, ${ }^{103}$ the objective approach it adopts is susceptible to subjective biases on the part of the fact finder. One well-documented bias in particular-hindsight bias-has come to take center stage in modern-day doctrinal debates. Because a nonobviousness determination must take place in the ex ante world just prior to the invention, it requires fact finders to disregard the ex post fact that the invention actually took place. ${ }^{104}$ Hindsight bias-people's subjective and unconscious tendency to incorrectly assign a high predictability to a past event based on their present knowledge that the event has, in fact, occurred-makes this exercise very difficult. ${ }^{105}$ In other words, in hindsight, most inventions are cognitively obvious. Hindsight bias can also affect a purely economic nonobviousness inquiry. In practice, whether a person or entity would "find it economically obvious to undertake the research necessary for success," 106 requires understanding how a researcher would have reacted to market forces present at the time of the invention. Absent clear, objective market demand and firm behavior data, fact finders' assessments of the likelihood the market would have given rise to the invention are likely to be inflated by seeing the finished, successful invention.

Concerned about the impact of hindsight bias on innovation incentives, the Federal Circuit's nonobviousness jurisprudence

\footnotetext{
100 Id at $17-18$.

101 See, for example, Environmental Designs, Ltd v Union Oil Co of California, 713 F2d 693, 697-98 (Fed Cir 1983) (using “expressions of disbelief” by experts as an objective

102 See, for example, Intercontinental Great Brands LLC v Kellogg North America Co, 869 F3d 1336, 1345-47 (Fed Cir 2017) (explaining that "objective indicia is evidence to be weighed in the overall legal determination of obviousness").

103 See Graham, 383 US at 15 ("It also seems apparent that Congress intended by the last sentence of $\S 103$ to abolish the test it believed this Court announced in the controversial phrase 'flash of creative genius,' used in Cuno.”).

104 In a series of articles, Professor Gregory Mandel has tested the effect of hindsight on nonobviousness decisions. See generally Mandel, 67 Ohio St L J 1391 (cited in note 26); Gregory N. Mandel, A Nonobvious Comparison: Nonobviousness Decisions at the PTAB and in the Federal Courts, 24 Tex Intell Prop L J 403 (2016).

105 See Mandel, 12 Lewis \& Clark L Rev at 336-37 (cited in note 6).

106 Abramowicz and Duffy, 120 Yale L J at 1655 (cited in note 4).
} indicator). 
has focused on eliminating hindsight bias and increasing the predictability of the nonobviousness doctrine through the TSM test. ${ }^{107}$ The TSM test provided a gloss on the Graham framework that required a specific finding that "the prior art would have suggested to one of ordinary skill in the art that [a particular combination of references] should be carried out and would have a reasonable likelihood of success." 108 In its strictest application, the TSM test required the PTO and courts to make a "clear and particular" 109 showing of a suggestion to combine prior art references by "point[ing] to particular items of prior art that concretely suggest[ed] how to combine all of the features of a claimed invention." 110 In short, under the TSM test, a showing of obviousness required that the prior art explicitly suggest the particular recombination present in the invention. ${ }^{111}$ Under this test-recourse to common sense, which may suggest that an invention was an obvious combination of existing prior art—was an impermissible exercise in hindsight bias. ${ }^{112}$

An important shortcoming of the TSM test, however, was that it ignored the tacit, unarticulated knowledge available to inventors. To guard against hindsight bias, the TSM test treated persons of skill in the art as unable to take any steps beyond what was explicitly articulated in existing prior art references. The TSM test also all but erased considerations about the impact of market and social forces on innovation without patent protection. The Federal Circuit's reliance on the TSM test as the sole test for patent nonobviousness was ultimately challenged before the Supreme Court in $K S R$.

In KSR, the Supreme Court criticized the TSM test as "rigid" and inflexible-leading to excessive patent grants that stifled

107 See, for example, Loctite Corp v Ultraseal Ltd, 781 F2d 861, 873 (Fed Cir 1985) ("In patent cases, the need for express Graham findings takes on an especially significant role because of an occasional tendency of district courts to depart from the Graham test, and from the statutory standard of unobviousness that it helps determine, to the tempting but forbidden zone of hindsight."); In re Dembiczak, 175 F3d 994, 999 (Fed Cir 1999) (emphasizing the importance of a "rigorous application of the requirement for a showing of the teaching or motivation to combine prior art references" to combat the "subtle but powerful attraction of a hindsight-based obviousness analysis").

108 Brown and Williamson Tobacco Corp v Philip Morris, Inc, 229 F3d 1120, 1124 (Fed Cir 2000) (emphasis added).

109 Dembiczak, 175 F3d at 999.

110 Federal Trade Commission, To Promote Innovation: The Proper Balance of Competition and Patent Law and Policy *12 (Oct 2003), archived at https://perma.cc/ PS4T-GWND.

111 See Dembiczak, 175 F3d at 999.

112 Id at $999-1000$. 
follow-on innovation. ${ }^{113}$ In its stead, the Court called for a return to the tripartite Graham framework and a focus on those economic and "common sense" factors that would indicate whether an innovation would likely take place without patent protection. ${ }^{114}$ For example, the Court emphasized the importance of understanding that "design incentives and other market forces," 115 as well as exogenous technological developments may prompt ordinary artisans to combine references, especially if those combinations lead to predictable results. ${ }^{116}$ The Court also emphasized that a PHOSITA is not an "automaton" devoid of any creativity; rather, a PHOSITA can be expected to take incremental inventive steps. ${ }^{117}$ Applying these common sense and economic elements to the particular facts before it, the Court in KSR held that adding an electronic sensor to a moveable vehicle pedal assembly was obvious in light of the exogenous technological development of electronic sensors, and the increasing market demand for modifying adjustable vehicle pedal assemblies with such electronic sensors. ${ }^{118}$

The KSR framework corrected important mistakes in TSM jurisprudence by curtailing patent grants for insignificant inventions in crowded fields, or in inventions for which market forces or exogenous technological developments were sufficient incentives. ${ }^{119}$ Yet, $K S R$ 's flexible framework also increased the overall unpredictability of patent nonobviousness decisions. One aspect of $K S R$ in particular-its endorsement of the use of "common sense"-has injected hindsight bias back into the nonobviousness analysis. While seemingly endorsing an economic view of nonobviousness, the Court in $K S R$ left unclear how to incorporate an understanding of "design incentives and other market forces" 120 into the nonobviousness analysis: How should judges attempt to measure such market forces? When are market forces sufficient to tip the balance toward obviousness? This indeterminacy has opened the door for an increasing reliance on judicial "common sense" that may not reflect economic realities. Empirical data on nonobviousness decisions post-KSR indicate that both

113 KSR, $550 \mathrm{US}$ at $419,427-28$.

114 Id at $416-20$.

115 Id at 417 ("When a work is available in one field of endeavor, design incentives and other market forces can prompt variations of it, either in the same field or a different one."). 116 Id.

$117 \mathrm{KSR}, 550 \mathrm{US}$ at 421.

118 Id at $423-25$.

119 See, for example, Jason Rantanen, The Federal Circuit's New Obviousness Jurisprudence: An Empirical Study, 16 Stan Tech L Rev 709, 736-37 (2013).

$120 \mathrm{KSR}, 550 \mathrm{US}$ at 417. 
district courts and the Federal Circuit are indeed increasingly relying on "common sense" or on "the nature of the problem facing the inventor" to explain why a particular combination of references should be found obvious. ${ }^{121}$ And, taking to heart the Supreme Court's admonition to consider a PHOSITA's ability to think creatively, the Federal Circuit has become more likely to uphold a district court's finding of obviousness than a finding of nonobviousness. ${ }^{122}$

These two ways of conceptualizing nonobviousness that emerged in doctrinal cases have their counterparts in the academic literature, reflected in two strands of theoretical writings: one emphasizing how to use insights from economics to define nonobviousness, the other emphasizing how to integrate psychological research on creativity to the nonobviousness inquiry. In turn, these two theoretical frameworks generate different doctrinal prescriptions for how to measure nonobviousness in specific cases. The next Section provides brief analyses of these two theoretical perspectives.

\section{B. Theoretical Perspectives: Economic and Psychological} Models of Nonobviousness

Law and economics scholars have advanced a number of models to explain and justify the nonobviousness requirement. What all of these models have in common is a recognition that patents should be granted only in cases of market failure, that is, when market forces alone are insufficient to bring about the invention. Where they differ is in the variables that they emphasize as predictive of such market failures. Below we describe three models, which we term: (1) the "uncertainty" model; (2) the "social value" model; and (3) the "inducement" model.

121 See, for example, Rantanen, 16 Stan Tech L Rev at 759-60 (cited in note 119) ("Almost every time the Federal Circuit has applied a reason to combine analysis since $K S R$, it has articulated the requirement in such a way that places no limits, express or implied, on how it may be satisfied.").

122 Id at 744-45 ("[T] nals reach conclusions that patents are obvious."); Jennifer Nock and Sreekar Gadde, Raising the Bar for Nonobviousness: An Empirical Study of Federal Circuit Case Law Following KSR, 20 Fed Cir Bar J 369, 371, 399-400 (2011) ("The Federal Circuit is now much less likely to reverse a lower-tribunal finding that a patent is obvious than a finding that a patent is nonobvious."). 
Professor Robert Merges has proposed an "uncertaintybased" economic model of nonobviousness. ${ }^{123}$ In this model, the nonobviousness standard would "reward[] one who successfully invents when the uncertainty facing her prior to the invention makes it more likely than not that the invention won't succeed."124 The model goes on to tie uncertainty to cost: because uncertainty regarding the success of a particular invention or idea is costly to dispel, firms will prefer-all other things being equal-to invest in inventions with low uncertainty (and therefore low cost). ${ }^{125}$ In this view, the nonobviousness doctrine prevents the patenting of low-hanging fruit: those inventions that are not costly to discover and develop because of a low likelihood of failure. ${ }^{126}$ This "uncertainty" view of nonobviousness is consistent with the economic perspective that underlies both the Graham and KSR decisions. $K S R$ in particular emphasizes the role of "predictability" in assessing nonobviousness: "If a person of ordinary skill [in the art] can implement a predictable variation," and would see the benefit of doing so, "§ 103 likely bars its patentability." 127 A renewed emphasis on predictability, understood as the likelihood that a particular research path will be successful ex ante, aligns with the uncertainty model.

A second model, the social value model, views the role of nonobviousness as nudging inventors to pursue more technically difficult, socially preferred research projects. ${ }^{128} \mathrm{~A}$ key insight of this model is that, in a world without the nonobviousness doctrine, firms would consistently choose to pursue those research projects that maximize the difference between expected private value and cost. ${ }^{129}$ From a utilitarian perspective, however, governments grant patents to incentivize socially optimal-not just privately optimal-investment. Socially optimal projects, however, tend to

123 Merges, 7 High Tech L J at 19-20, 34 (cited in note 28).

124 Id at 19 (emphasis omitted). A related interpretation of risk, advanced by Professor William Landes and Judge Richard Posner, ties uncertainty to cost. When creating knowledge, and thus dispelling uncertainty, is costly, firms will tend to wait for competitors to make the initial investment and then copy the final product. As a consequence, all firms will underinvest in knowledge goods absent patent protection. Posner and Landes, The Economic Structure of Intellectual Property Law at 304-05 (cited in note 28).

125 Merges, 7 High Tech L J at 47-48 (cited in note 28) ("One practical way to assess whether a project involve[s] a high degree of risk is to look at the cost.”).

126 Id at 47-49.

$127 K S R, 550$ US at 417.

128 See, for example, Meurer and Strandburg, 12 Lewis \& Clark L Rev at 549 (cited in note 28); Lunney, 7 Mich Telecomm \& Tech L Rev at 368 (cited in note 28).

129 Meurer and Strandburg, 12 Lewis \& Clark L Rev at 549, 560-65 (cited in note 28). 
be more technically ambitious than privately optimal ones. ${ }^{130}$ Therefore, the nonobviousness doctrine can be conceptualized as a tool to shift the choice of research projects toward socially preferred ones. ${ }^{131}$ The first and second models are in fact linked: Socially optimal innovation tends to be more technically difficult, more costly, and more risky than the privately optimal alternatives. ${ }^{132}$ On the other hand, privately optimal projects may consist of small tweaks or improvements to already commercially successful (or already commercially established) products, rather than breakthrough or disruptive innovation. ${ }^{133}$

Finally, Professors Michael Abramowicz, John Duffy, and Tun-Jen Chiang have developed inducement models that seek to operationalize the economic standard articulated by the Court in Graham. ${ }^{134}$ Their reformulation of the standard contains two important refinements. First, they incorporate the element of time, seeking to identify those inventions which would not have been disclosed or devised for a substantial period of time, as deserving of patent protection. ${ }^{135}$ Second, the inducement model embraces

130 Id at 549 ("[W]here, as is realistically nearly always the case, the social value of research projects substantially exceeds their private value ... [t] he nonobviousness threshold may be used as a 'stick' to induce researchers to pursue more difficult, socially preferred research projects.”).

131 The two articles we have classified under the "social value" model similarly provide a compelling justification for the nonobviousness doctrine based on the gap between social value and private returns. They differ, however, in the way that each model accounts for the social value of innovation. In Professor Glynn Lunney Jr's model, social value is tied to the "creative investment fraction"-defined as "the creativity invested . . a as a fraction of the invention's total cost." Lunney, 7 Mich Telecomm \& Tech L Rev at 413 (cited in note 28). In Professors Michael Meurer's and Katherine Strandburg's model, the social value of innovation is tied instead to the extent to which a particular innovation generates knowledge spillovers-that is, social benefits that cannot be fully appropriated by the innovator. Meurer and Strandburg, 12 Lewis \& Clark L Rev at 560-65 (cited in note 28).

132 See Part II.A.

133 See, for example, Jeremy A. Greene and Kevin R. Riggs, Why Is There No Generic Insulin? Historical Origins of a Modern Problem, 372 New Eng J Med 1171, 1173, 1175 (2015) ("Nearly a century after its discovery, there is still no inexpensive supply of insulin for people living with diabetes in North America, and Americans are paying a steep price for the continued rejuvenation of this oldest of modern medicines.").

134 We adopt the name "inducement model" from Abramowicz and Duffy's work. See Abramowicz and Duffy, 120 Yale L J at 1593 (cited in note 4), quoting Graham, 383 US at 11. Chiang's "cost-benefits" approach, which focuses on predicting when an independent inventor would have developed the invention without patent protection, also fits within this larger type of economic model. See Chiang, 82 St John's L Rev at 42 (cited in note 28) ("An invention should receive a patent if the accrued benefits before independent invention outweigh the costs after independent invention.").

135 See Chiang, 82 St John's L Rev at 64-67 (cited in note 28) (analyzing whether a patent should be granted based on whether "benefits exceed costs" in "the period between the patentee's invention and a later independent invention"); Abramowicz and Duffy, 120 Yale L J at 1626-30 (cited in note 4) (arguing that the Graham test for nonobviousness 
an economic definition of a PHOSITA that focuses on whether, in the absence of patents, a person or entity would "find it economically obvious to undertake the research necessary for success." 136 This refinement is an important departure from current doctrinal practice-indeed, it is in their definition of a PHOSITA as an artisan of "ordinary skill" that cognitive understandings of nonobviousness remain embedded into the nonobviousness doctrine. ${ }^{137}$ This economic definition of a PHOSITA also incorporates concerns about uncertainty and cost, and is therefore compatible with Merges's view of nonobviousness as incentivizing uncertain innovation. A highly uncertain and/or costly innovation would likely not be economically obvious absent patent protection. ${ }^{138}$ Similarly, a socially optimal research path (under the social value model) would likely be economically nonobvious when compared to the privately optimal path.

In contraposition to the other two economic models which do not seek to turn their insights into specific doctrinal frameworks, the inducement model identifies particular economic contexts that are likely to facilitate invention without patent protection. ${ }^{139}$ Specifically, Abramowicz and Duffy note that inventions are likely obvious when they take place (1) after a surge of market demand; and (2) as a by-product of exogenous technological developments. ${ }^{140}$

These three economic approaches to nonobviousness, however, have struggled to develop doctrinal tests that can easily and accurately capture instances of market failures. Many of the contextual economic factors needed to assess the economic nonobviousness of an invention are quite hard, if not impossible, for the

should include a temporal element that "requir[es] the inducement of a patent to accelerate invention by a substantial period of time").

136 Abramowicz and Duffy, 120 Yale L J at 1655 (cited in note 4).

137 Id at 1663 (cited in note 4) ("[T]he PHOSITA obviousness test can accommodate [economic and cognitive] insights as long as the test no longer isolates the PHOSITA's state of mind regarding technology from economic considerations.").

138 See id ("[W]hether an invention is obvious depends on how costly an experiment would be and the probability that the experiment would be successful.").

139 The authors identify two circumstances: a "positive demand shock shortly before the invention," and a "rapidly declining cost of invention" as proxies showing that a patent is unnecessary to induce a particular innovation. Id at 1656.

140 See Abramowicz and Duffy, 120 Yale L J at 1656, 1676-77 (cited in note 4). An exogenous technical development could drastically reduce the costs of innovation or amplify the benefits. "For example, if an invention depends on a research tool that did not exist until shortly before the research leading to the invention, the invention could not have been invented earlier." The development of such "an exogenous shock that decreases the cost of an invention ... should count as a secondary consideration of obviousness." Id at 1677 . 
PTO to evaluate. ${ }^{141}$ For instance, Abramowicz and Duffy emphasize that a surge of market demand just prior to the invention strongly suggests that the invention is economically obvious. ${ }^{142}$ But assessing market demand is outside the expertise of patent examiners. The same is true of assessing whether an exogenous technological advance took place around the date of invention. Such an assessment requires the type of meta-analysis of innovation trends that the PTO is not equipped to carry out. Courts can fare better in making this type of economic analysis. Nevertheless, the Federal Circuit has used flawed heuristics to assess existing market forces (such as the commercial success of an invention, or its unexpected results), failing to engage with an in-depth analysis of market shocks or exogenous factors. ${ }^{143}$ Proponents of the economic approach themselves have warned against facile applications of economic theory and called for the gathering of additional empirical data to develop objective nonobviousness measures. ${ }^{144}$

Psychological theories of nonobviousness share a fundamental concern with economic perspectives: the goal of patent law should be to incentivize socially valuable innovation. ${ }^{145}$ Thus, psychological perspectives on nonobviousness begin with the insight

141 The Court in Graham made clear that "the primary responsibility for sifting out unpatentable material lies in the Patent Office," thus highlighting the importance of developing a nonobviousness test that can be applied both by the PTO and the courts. Graham, 383 US at 18.

142 Abramowicz and Duffy, 120 Yale L J at 1656 (cited in note 4).

143 See, for example, Pedraza-Fariña, $2013 \mathrm{Wis}$ L Rev at 824-25, 870-72 (cited in note 54); Mark A. Lemley, Expecting the Unexpected, 92 Notre Dame L Rev 1369, 1387-89 (2017).

144 See, for example, Lunney, 7 Mich Telecomm \& Tech L Rev at 417 (cited in note 28) (calling for the development of a "base of empirical data and experience with the creative investment fraction approach" to help "determine the precise creative investment fraction that the nonobviousness standard should require to support patentability"); Meurer and Strandburg, 12 Lewis \& Clark L Rev at 573 \& n 77 (cited in note 28); Chiang, 82 St John's L Rev at 75 (cited in note 28) ("As with any theoretical standard, applying the theory to reality requires empirical data that is not usually available. The key variables of benefit, cost, and timing of independent invention are difficult to predict before the patent is issued.").

145 See, for example, Fromer, $104 \mathrm{Nw} \mathrm{U} \mathrm{L} \mathrm{Rev} \mathrm{at} \mathrm{1457-59} \mathrm{(cited} \mathrm{in} \mathrm{note} \mathrm{30);}$ Buccafusco, et al, 92 Tex L Rev at 1931-32 (cited in note 30). Economic theorists, however, often reject cognitive interpretations of the nonobviousness standard, which center on the degree of cognitive difficulty in coming up with an invention. For example, Abramowicz and Duffy argue that a cognitive approach is particularly ill-equipped at helping draw the line between obvious and nonobvious inventions, because "cognition is an epistemic phenomenon that takes place at a particular moment in time while invention occurs across time." Abramowicz and Duffy, 120 Yale L J at 1608 (cited in note 4). Meurer and Strandburg similarly criticize what they term the "technical view of nonobviousness" (in other words, a view of nonobviousness that focuses only on whether the problem faced by 
that innovation and creativity are inextricably linked. Proponents of a psychological perspective view the core of intellectual property law (and patent law in particular) as concerned with providing inventors incentives to act creatively. ${ }^{146}$ Understanding how the creative process unfolds becomes crucial to designing a system of incentives to promote creativity. Understanding the creative process also provides tools that complement more traditional economic analyses of innovation. Despite efforts by law and economic scholars to operationalize an economic view of patent law (and of nonobviousness in particular), it is often impossible to determine whether, for any specific invention, a patent incentive was necessary to bring it about. ${ }^{147}$ As Professor Jeanne Fromer argues, "By examining creativity, the activity that copyright and patent law each seek to stimulate, instead of examining the economic impact of these laws, we can begin to understand better how to structure these laws to induce valuable creativity." 148

Psychologists generally agree on a core definition of creativity that contains two elements: (1) novelty and (2) appropriateness. ${ }^{149}$ The concept of novelty is fairly self-explanatory: recreating or performing someone else's solution to a problem is not novel, and therefore not creative. Appropriateness refers to whether an idea is "recognized as socially valuable in some way to some community," and is therefore context dependent. ${ }^{150}$ Social psychologist Teresa Amabile adds a third element to her definition of creativity: (3) the task must be "heuristic rather than algorithmic." As Amabile explains, "algorithmic tasks are those for which the path to the solution is clear and straightforward-tasks for which an

the inventor was technically easy or hard) for ignoring contextual economic and social factors that would influence whether a patent is needed to bring about a particular invention. Meurer and Strandburg, 12 Lewis \& Clark L Rev at 571-72 (cited in note 28).

146 See, for example, Fromer, $104 \mathrm{Nw} \mathrm{U} \mathrm{L} \mathrm{Rev} \mathrm{at} \mathrm{1457-59} \mathrm{(cited} \mathrm{in} \mathrm{note} \mathrm{30);}$ Buccafusco, et al, 92 Tex L Rev at 1931-32 (cited in note 30).

147 Fromer, $104 \mathrm{Nw}$ U L Rev at 1458-59 (cited in note 30) ("Existing legal and economic scholarship acknowledges the difficulty, if not impossibility, of empirically testing whether particular patent laws encourage innovation. . . . The number of variables necessary to measure the effectiveness of intellectual property laws simply cannot easily be held constant to produce reliable evidence.").

148 Id at 1459 (cited in note 30). See also Davidson and Greenberg, 12 Lewis \& Clark L Rev at 542-43 (cited in note 30 ).

149 Buccafusco, et al, 92 Tex L Rev at 1932-33 (cited in note 30); Teresa M. Amabile, The Social Psychology of Creativity: A Componential Conceptualization, 45 J Personality \& Soc Psychology 357, 360 (1983).

150 R. Keith Sawyer, Explaining Creativity: The Science of Human Innovation 9 (Oxford 2012). See also Buccafusco, et al, 92 Tex L Rev at 1932-33 (cited in note 30) ("Assessing creativity [and the appropriateness of an invention] is not complete without reference to a work's effect on the relevant culture and its social judgments."). 
algorithm exists." ${ }^{151}$ In contrast, "heuristic tasks are those not having a clear and readily identifiable path to solution-tasks for which algorithms must be developed." 152 The contrast between algorithmic and heuristic tasks approximates the Supreme Court's efforts in KSR to distinguish "ordinary" or "routine" from "real" innovation. Reframed as a psychological inquiry, the nonobviousness doctrine would seek to reward, and therefore incentivize, those creative innovations that are not algorithmic - that is, those for which a clear, predictable path to a solution cannot be specified at the outset.

One important insight in creativity research is that creative insights are often recombinations of mental concepts: the most creative of those recombinations tend to be those that combine distant, dissimilar concepts. ${ }^{153}$ This is because, as Professor Keith Sawyer explains, "When concepts are very different, you have to use the more complex [mental] strategies of property mapping or structure mapping, and these strategies result in the most novel and innovative combinations." 154 In other words, particularly creative inventions are often those that combine dissimilar concepts or ideas that have not previously been combined. As we argue in Part II.C, this particular type of creativity, in which disparate domains are brought together, serves as a good proxy for economic nonobviousness.

The mental processes involved in creative performance also include several biases that can impede both creative insights and an objective appreciation of such creative insights. As we discussed in the previous Section, doctrinal discussions of nonobviousness have focused on one particular bias-hindsight bias. Hindsight bias has been well-documented in the psychological and legal literature. ${ }^{155}$ The bias makes it impossible for an observer (be it a judge or a jury), having access to the information relevant to solve a problem and to the correct framing of the problem that led to its solution, to fully appreciate moments of insight. ${ }^{156}$ What psychological studies show is that hindsight bias is

151 Amabile, 45 J Personality \& Soc Psychology at 360 (cited in note 149).

152 Id.

153 See Davidson and Greenberg, 12 Lewis \& Clark L Rev at 533 (cited in note 30).

154 Sawyer, 12 Lewis \& Clark L Rev at 467-68 (cited in note 30).

155 See generally Rebecca L. Guilbault, et al, A Meta-Analysis of Research on Hindsight Bias, 26 Basic \& Applied Soc Psychology 103 (2004) (building on ninety-five prior studies of hindsight bias to conduct a meta-analysis of the phenomenon).

156 For studies documenting the effect of hindsight bias in patent proceedings, see generally Mandel, 67 Ohio St L J 1391 (cited in note 26); Mandel, 24 Tex Intell Prop L J 403, 413-15, 425-26 (cited in note 104). 
particularly problematic when creativity emerges from "mental restructuring"- the realization that previously overlooked information is relevant for solving a problem or, conversely, that pieces of information are irrelevant (and distracting). ${ }^{157}$ Choosing what to pay attention to (and what not to) is crucial for problem solving, but patent examiners and judges always have before them all the relevant information necessary to solve the problem as framed by the inventor. In short, hindsight bias prevents observers from appreciating truly creative inventions as such.

Psychological theories of nonobviousness lead to a cognitive doctrinal framework aimed at identifying and rewarding creative inventions (in other words, those embodying novel, appropriate, and heuristic ideas) while avoiding hindsight bias that prevents observers from appreciating such creativity ex post. But psychological theorists have also struggled to translate these conceptual insights into easily applicable doctrinal frameworks. First, although psychological theory emphasizes the pervasiveness of hindsight bias, it provides no clear way to debias observers. To the contrary, most experiments on hindsight bias show it to be persistent and resistant to debiasing interventions. ${ }^{158}$ Second, creativity exists on a continuum, and psychological theories cannot answer the important question where to draw the line between obvious and nonobvious inventions or even how to measure where an invention might be on that creativity continuum.

In brief, there are two theoretical answers to the conceptual question: What is a nonobvious invention? Both of them are reflected in judicial opinions. The first answer, an economic one, ties nonobviousness to market failures. Simply put, nonobviousness should weed out those inventions for which the inducement of a patent is unnecessary. The second answer, a psychological one, ties nonobviousness to creativity. In this view, only creative, nonalgorithmic inventions should be granted patent protection. The two views are potentially reconcilable if one views the psychological perspective as a proxy for economic inducement in a subset of cases-a view we advance in Part II. Both of these theoretical

157 See Davidson and Greenberg, 12 Lewis \& Clark L Rev at 530-33 (cited in note 30).

158 See, for example, Mandel, 67 Ohio St L J at 1402-03 (cited in note 26) (collecting sources that explain how "[t]he hindsight bias has proven remarkably unyielding to varied efforts to ameliorate its impact"); Davidson and Greenberg, 12 Lewis \& Clark L Rev at 539 (cited in note 30) ("Hindsight bias is poisonous for the nonobviousness requirement in patent law. Even though the Supreme Court thinks it sufficient for patent examiners and courts simply to be aware of, and cautious about, hindsight bias, research presents a compelling case that this bias is impervious to change."). 
approaches have struggled to guide the development of clear doctrinal tests that can protect against hindsight bias, while incorporating contextual factors-such as surges in market demandthat would drive innovation without patent protection.

We take the economic approach as the largely correct conceptual interpretation of nonobviousness under a utilitarian framework. The ultimate goal of patent law, as embedded in the US Constitution, is a utilitarian one. ${ }^{159}$ We grant patent protection because the social benefits derived from such protection outweigh the social costs of patents' limited monopoly. Under this framework, the inducement standard in Graham and KSR represents the clearest articulation of the cost-benefit balance embedded in patent law. When market competition would suffice to bring about an invention, granting patent protection to such invention would represent a net cost to society.

Our theoretical analysis of the nonobviousness requirement, which we undertake in the next Part, proposes several important refinements to this economic view. First, we note that the market forces emphasized by economic views (demand surges and exogenous technological developments) fail to capture important structural determinants to innovation. ${ }^{160}$ By identifying innovationspecific factors that make innovation more or less risky, predictable, and costly, our network perspective both complements and deepens current economic understandings of nonobviousness. Second, we show how some psychological understandings of creativity that emphasize boundary-crossing can serve as useful proxies for economic nonobviousness. Finally, we operationalize a network view of innovation by creating a network measure of nonobviousness (the network nonobviousness score, NNOS), which we explain in Part III. We argue that our approach represents the best attempt to date to simultaneously reduce hindsight bias and incorporate the impact of market and social forces into the nonobviousness inquiry.

159 See, for example, Mark A. Lemley, Faith-Based Intellectual Property, 62 UCLA L Rev 1328, 1338-44 (2015) (criticizing nonutilitarian approaches to patent law).

160 See Pedraza-Fariña, 70 SMU L Rev at 423-24 (cited in note 37) (describing three types of structural barriers to innovation: lack of social ties, cognitive distance, and different—or clashing—evaluative frames). 


\section{MODELING INNOVATION AS A SEARCH AND RECOMBINATION PROCESS: IMPLICATIONS FOR NONOBVIOUSNESS THEORY AND DOCTRINE}

In recent years there has been a growth in research that not only attempts to understand the incentives or cognitive processes underlying innovation, but that also focuses on the social and structural elements most likely to produce socially impactful, breakthrough innovation. This line of research focuses on understanding and modeling how inventors search and build upon existing knowledge to generate new ideas. More specifically, scholars have turned to network perspectives to understand how different patterns of information recombination and distinct network structures are likely to lead to different qualities of innovation. Although network perspectives on innovation have had a wide-ranging influence on our social scientific understanding of what brings about high-quality inventions, as of yet neither legal scholars nor patent system administrators have integrated this valuable knowledge into patent theory and doctrine.

A. Innovation as Search and Recombination Across

\section{Information Networks}

Networks can provide powerful insight into how high-impact, new ideas are generated. For instance, examining structural holes-arising between two areas of a network that are relatively well-connected within themselves but poorly connected to one another-can help us identify potential sources of breakthrough ideas. Individuals who bridge these structural holes "are at higher risk of having good ideas," 161 by virtue of having access to more diverse information and "alternative ways of thinking and behaving." 162 These actors_-"brokers" 163 or "boundary-spanners"164 in the terminology of network analysis - can leverage their access to multiple knowledge communities to come up with ideas that others see as unusually "creative." 165

161 Ronald S. Burt, Structural Holes and Good Ideas, 110 Am J Soc 349, 349-50 (2004). 162 Id at 375 n 13 (cited in note 161).

163 See, for example, Ronald S. Burt, Brokerage and Closure: An Introduction to Social Capital 11-18 (Oxford 2005); Lee Fleming and David M. Waguespack, Brokerage, Boundary Spanning, and Leadership in Open Innovation Communities, 18 Org Sci 165, 165-66 (2007). 164 See generally Fleming and Waguespack, 18 Org Sci at 169-70 (cited in note 163); Rob Cross, Chris Ernst, and Bill Pasmore, A Bridge Too Far? How Boundary Spanning Networks Drive Organizational Change and Effectiveness, 42 Org Dynamics 81, 81-82 (2013).

165 Burt, 110 Am J Soc at 387-88 (cited in note 161). 
Structural holes are an example of a social network structural signature that corresponds to the generation of new ideas. Related notions such as "weak ties,"166 "boundary spanning,"167 and "structural folds" 168 all demonstrate that joining disparate or weakly connected portions of a social network can lead to valuable intermingling of information that otherwise would not be recombined. These findings also extrapolate to information networks, in which the underlying network represents not social connections, but rather the connection between units of information, such as patents or scientific articles. For instance, research demonstrates that when scientists make atypical combinations of information inputs, they are more likely to generate high-impact science. ${ }^{169}$ The underlying notion is that by combining rarely combined types of scientific knowledge, researchers are more likely to generate ideas that break new scientific ground and open new avenues for future research. Related studies, such as those demonstrating that boundary-spanning research is more likely to be high impact ${ }^{170}$ or that rare combinations of information input can generate technological breakthroughs, ${ }^{171}$ show that these findings demonstrating the value of information network measures are robust.

These robust findings about the relationship between highimpact innovation and distant knowledge recombination have led innovation theorists to coin a term for this model of innovation: the "tension model." 172 It is so-called because of the inherent

\footnotetext{
166 See generally Mark S. Granovetter, The Strength of Weak Ties, 78 Am J Soc 1360 (1973); Morten T. Hansen, The Search-Transfer Problem: The Role of Weak Ties in Sharing Knowledge Across Organization Subunits, 44 Admin Sci Q 82 (1999).

167 See, for example, Howard Aldrich and Diane Herker, Boundary Spanning Roles and Organization Structure, 2 Acad Mgmt Rev 217, 221-22 (1977); Ryan Whalen, Boundary Spanning Innovation and the Patent System: Interdisciplinary Challenges for a Specialized Examination System, 47 Rsrch Pol 1334, 1340 (2018).

168 See, for example, Balázs Vedres and David Stark, Structural Folds: Generative Disruption in Overlapping Groups, 115 Am J Soc 1150, 1151-52 (2010); Mathijs de Vaan, David Stark, and Balázs Vedres, Game Changer: The Topology of Creativity, 120 Am J Soc 1144, 1145-47 (2015).

169 Brian Uzzi, et al, Atypical Combinations and Scientific Impact, 342 Science 468, 471 (2013).

170 See, for example, Xiaolin Shi, et al, The Impact of Boundary Spanning Scholarly Publications and Patents, 4 PLOS ONE 1, 6 (2009) ("We found that among patent inventions ... those who cite across disciplines tend to garner more citations, indicating that cross-fertilization of ideas does often lead to significant impact.").

171 See, for example, Lee Fleming, Recombinant Uncertainty in Technological Search, 47 Mgmt Sci 117, 130-31 (2001).

172 See, for example, Sarah Kaplan and Keyvan Vakili, The Double-Edged Sword of Recombination in Breakthrough Innovation, 36 Strategic Mgmt J 1435, 1435-36 (2015);
} 
tension between the need for deep domain expertise required to identify potentially fruitful problems and lines of inquiry, and the need for broad knowledge search, translation, and recombination required to produce high-impact innovation. ${ }^{173}$ Research exploring the tension model of innovation has shown that "distant and diverse recombinations are positively associated with economic value." 174 Underlying the tension model of innovation is a conception of innovation as arising from information search and recombination processes that occur within information and social networks. ${ }^{175}$ By understanding that innovators work within networks, and information can be thought of in terms of connections and distances, a network approach to innovation has enabled researchers to more concisely understand what leads to highimpact innovation and to typify different types of creativity.

\section{B. Network Distance as a Proxy for Market Failures in Innovation}

Modeling innovation as a search and recombination process occurring within information and social networks can help clarify the nonobviousness doctrine both as a conceptual matter and in application. As we summarized in Part I, an economic theory of nonobviousness - which we largely adopt_views the goal of the nonobviousness doctrine as providing incentives to help overcome market failures within the innovation system. Conceptually, a

Tommaso Savino, Antonio Messeni Petruzzelli, and Vito Albino, Search and Recombination Process to Innovate: A Review of the Empirical Evidence and a Research Agenda, 19 Intl J Mgmt Rev 54, 65-68 (2017) (reviewing empirical evidence supporting a search and recombination or "tension" model of innovation).

173 See Kaplan and Vakili, 36 Strategic Mgmt J at 1435 (cited in note 172).

$174 \mathrm{Id}$ at 1437. See also Gautam Ahuja and Curba Morris Lampert, Entrepreneurship in the Large Corporation: A Longitudinal Study of How Established Firms Create Breakthrough Inventions, 22 Strategic Mgmt J 521, 526-28, 539 (2001); Gautam Ahuja, Curba Morris Lampert, and Vivek Tandon, Moving Beyond Schumpeter: Management Research on the Determinants of Technological Innovation, 2 Acad Mgmt Annals 1, 65 (2008) (demonstrating that "innovation output can be increased by enhancing the recombinatory set ... that can be accessed by a firm").

175 This view of innovation as a search and recombination process dates back to work by Professor Joseph Schumpeter and continues to represent the dominant model of innovation within the organizational economics and management literature. See, for example, Ahuja, Lampert, and Tandon, 2 Acad Mgmt Annals at 65-68 (cited in note 174) (arguing that "[r]ecombinatory search models are the implicit underlay for a large body of work on innovation," and summarizing theoretical and empirical analyses of innovation as a search and recombination process); Satyam Mukherjee, et al, A New Method for Identifying Recombinations of Existing Knowledge Associated with High-Impact Innovation, $33 \mathrm{~J}$ Prod Innovation Mgmt 224, 232-33 (2015); Savino, Petruzzelli, and Albino, 19 Intl J Mgmt Rev at 60-64 (cited in note 172) (collecting and reviewing studies based on a search and recombination theory of innovation). 
search and recombination model of innovation can help identify such instances of market failures, especially those arising from the cost and uncertainty of return on investment. ${ }^{176}$ Both innovation cost and uncertainty can be thought of in network terms.

The cost and uncertainty of research rises as a function of both the search and the recombination processes. The search process involves seeking information inputs to use in the production of new inventions. In broad terms there are two types of search behavior: local search and global search. ${ }^{177}$ Local search entails investment of research resources within the field, and often leads to improvement inventions or inventions that, although they may break new ground, do so within an existing domain rather than by integrating distant knowledge. ${ }^{178}$ Some drug innovations would fit within the local search paradigm, as they begin from established theories of medical science and much of the research processes involves "searching" through chemical compound alternatives in an attempt to find the most effective treatments. ${ }^{179}$

On the other hand, global search involves seeking through distant information resources and recombining them to generate something new. ${ }^{180}$ For instance, an invention that allows for brain wave detection to articulate a prosthetic limb spans many diverse knowledge areas including robotics, neurology, and electrical engineering. Global searches tend to be more uncertain, and therefore also more costly, than local searches. ${ }^{181}$ The higher economic cost of global searches stems from a number of factors. Most important among them are, first, the costs of assembling a research team with the necessary diverse and deep domain expertise to

176 For a summary of the market failures arising from cost and uncertainty, see Part I.B.

177 See, for example, Ahuja, Lampert, and Tandon, 2 Acad Mgmt Annals at 65 (cited in note 174).

178 See Toby E. Stuart and Joel M. Podolny, Local Search and the Evolution of Technological Capabilities, 17 Strategic Mgmt J 21, 22 (1996); Victor Gilsing, et al, Network Embeddedness and the Exploration of Novel Technologies: Technological Distance, Betweenness Centrality and Density, 37 Rsrch Pol 1717, 1719 (2008) (explaining how, in a local search, "firms search for new knowledge that is less likely to conflict with their existing cognitive and mental models," and linking such local searches to processes of "[e]xploitation" of existing technologies, characterized by "routinisation, which adds to the existing knowledge base and competence set of firms without changing the nature of activities").

179 See, for example, William P. Janzen, Screening Technologies for Small Molecule Discovery: The State of the Art, 21 Chemistry \& Biology Rev 1162, 1162 (2014) (describing standardized protocols for screening through compound libraries to see which compound achieves a desired biological activity).

180 See Lori Rosenkopf and Atul Nerkar, Beyond Local Search: Boundary-Spanning, Exploration, and Impact in the Optical Disk Industry, 22 Strategic Mgmt J 287, 289 (2001).

181 See Stephanie Plamondon Bair and Laura G. Pedraza-Fariña, Anti-Innovation Norms, 112 Nw U L Rev 1069, 1128 (2018). 
understand how to search (and find) relevant information, and second, the subtler costs of bringing together diverse innovation communities with often divergent research priorities, methodological approaches, and evaluation processes. ${ }^{182}$ This second set of costs is linked to the transaction costs of breaking strong social norms within innovator communities that pull researchers into path-dependent local searches rather than broader global searches. ${ }^{183}$

Just as search can increase the uncertainty and cost of generating new inventions, so too can the recombination aspect of the search and recombination process. ${ }^{184}$ Recombination requires translating knowledge across fields and integrating diverse information sources. ${ }^{185}$ As such, all else being equal, the "distance" between the information recombined increases the cost of the recombination (or translation) process. ${ }^{186}$ This is the case because, in most instances, the network distance between technology areas correlates with cognitive distance-defined as the cognitive difficulties entailed in bringing two or more sets of information together. ${ }^{187}$ For instance, recombining information inputs from the

182 See, for example, Pedraza-Fariña, 70 SMU L Rev at 423-24 (cited in note 37); Laura G. Pedraza-Fariña, Constructing Interdisciplinary Collaboration: The Oncofertility Consortium as an Emerging Knowledge Commons, in Katherine J. Strandurg, Brett M. Frischmann, and Michael J. Madison, eds, Governing Medical Knowledge Commons 259, 260 (Cambridge 2017); Bair and Pedraza-Fariña, 112 Nw U L Rev at 1109, 1128 (cited in note 181$)$.

183 See, for example, Bair and Pedraza-Fariña, $112 \mathrm{Nw}$ U L Rev at 1109 (cited in note 181); Pedraza-Fariña, Constructing Interdisciplinary Collaboration at 260 (cited in note 182). See also Ahuja and Lampert, 22 Strategic Mgmt J at 521 (cited in note 174) (identifying "three organizational pathologies that inhibit breakthrough inventions: the familiarity trap-favoring the familiar; the maturity trap-favoring the mature; and the propinquity trap-favoring search for solutions near to existing solutions"); Ahuja, Lampert, and Tandon, 2 Acad Mgmt Annals at 65 (cited in note 174) (summarizing studies that demonstrate a "behavioral tendency towards local search").

184 See D. Charles Galunic and Simon Rodan, Resource Recombinations in the Firm: Knowledge Structures and the Potential for Schumpeterian Innovation, 19 Strategic Mgmt J 1193, 1195 (1998) (explaining how "[e]xchange costs" arise when knowledge must "be transferred across competence boundaries"); Savino, Petruzzelli, and Albino, 19 Intl J Mgmt Rev at 55 (cited in note 172) ("The criticalities and difficulties firms must face to integrate and utilize searched knowledge effectively are widely recognized.").

185 See, for example, de Vaan, Stark, and Vedres, 120 Am J Soc at 1145 (cited in note 168$)$.

186 See, for example, Savino, Petruzzelli, and Albino, 19 Intl J Mgmt Rev at 61 (cited in note 172) (summarizing studies showing that "combinations of diverse knowledge elements originating from multiple people with different backgrounds remain inherently difficult”).

187 See, for example, Bart Nooteboom, Learning by Interaction: Absorptive Capacity, Cognitive Distance and Governance, 4 J Mgmt \& Governance 69, 72-74 (2000); Stefan Wuyts, et al, Empirical Tests of Optimal Cognitive Distance, 58 J Econ Behav \& Org 277, 278 (2005) (explaining cognitive distance as arising from divergent modes of thinking that 
fields of paper manufacturing and cardboard manufacturing in general would entail lower recombination costs than recombining information from the domain of paper manufacturing with that from the domain of nanomaterials.

In addition to providing improved conceptual clarity about the expected cost of innovation, a network approach can also provide improved clarity about the expected benefit side of the equation. Those inventions that require extensive global search, or the recombination of distant information inputs to bridge large cognitive distances (or both), face increased uncertainty about their potential success. Research shows that this sort of research is more likely to produce high-impact output, but it is also more likely to fail. ${ }^{188}$ As a consequence, research involving global searches and the recombination of distant knowledge tends to be simultaneously more uncertain and more socially beneficial (when successful) than research involving local searches.

Considered from an economic perspective, the costs arising from search and recombination can lead to market failures when the expected private benefit from the invention is lower than its expected private cost, even though the expected social benefit from the invention exceeds the expected private cost. When this is the case, absent efficient patent incentives, inventions will not be induced in a timely fashion. A network perspective complements this economic conceptualization of the nonobviousness doctrine by providing greater insight into the nature of the costs and benefits incurred during the innovation process. By conceiving of innovation as a search and recombination process occurring across information and social networks, a network perspective can show more clearly how and why innovation costs are likely high for some types of inventions (such as those that recombine information inputs from distant parts of an information network) but not for others (such as those for which locating the inputs requires very low search costs because of their proximity to the origin field). ${ }^{189}$

evolve under "different conditions (national, regional and organizational culture, customs/habits, social norms/values, education, technologies, markets)"); Gilsing, et al, 37 Rsrch Pol at 1719-20 (cited in note 178) (modeling cognitive distance as technological distance)

188 See Fleming, $47 \mathrm{Mgmt}$ Sci at 130 (cited in note 171) (stating that "[i]nventors' experimentation with new ... combinations leads to less success on average, but it also increases the variability that can lead to breakthroughs").

189 As we consider in more detail in Part III, when we discuss specific changes to current nonobviousness doctrine, local recombination can also entail high costs if routine experiments are simply very costly. This is likely the case with drug innovation, in which 


\section{Boundary-Crossing Creativity as a Proxy for Market} Failures in Innovation

In addition to enriching current economic understandings of nonobviousness, taking a network approach to innovation also provides insight into psychological perspectives. 190 The creativity that lies at the heart of a social-psychological understanding of nonobviousness is essential in making connections between disparate parts of a network. Indeed, Steve Jobs, one of the most influential innovators of his generation, once explained that "[c]reativity is just connecting things ... [to] synthesize new things." 191 From a network perspective, inventions that represent technological "breakthroughs" tend to make atypical combinations and draw on knowledge areas that are distant from one another. ${ }^{192}$ Thus, these boundary-crossing inventions represent both creative leaps, as they require high levels of creativity to integrate distantly related knowledge, as well as areas of potential market failures requiring patent incentives. In short, creativity-understood specifically as bridging the cognitive distance between two or more knowledge domains - can serve as a strong proxy for economic nonobviousness.

Likewise, the distinction between algorithmic and heuristic research approaches that psychologists use to characterize creative and thus nonobvious innovation can be understood in network terms. Research drawing on inputs that are closely related to one another within the network is more likely to benefit from algorithmic research approaches. This type of research involving local search and recombination is likely to involve well-trodden technical areas where routines for answering typical domain questions-and thus algorithmic approaches-have evolved. On the other hand, research drawing on information inputs that are distant from one another is less likely to be amenable to algorithmic research approaches; rather, combining distant knowledge domains is likely to require novel, nonroutine troubleshooting

the need to screen through large quantities of compounds, together with clinical trials, can generate enormous costs. For this reason, innovation arising from local searches can sometimes require patent inducement. A useful feature of our doctrinal framework, however, is that it sorts innovation into two distinct buckets-local and global recombination-and proposes innovation-specific factors that would inform whether a specific innovation in either category is likely to require the inducement of a patent.

190 See Part I.B.

191 Gary Wolf, Steve Jobs: The Next Insanely Great Thing (Wired, Feb 1, 1996), archived at https://perma.cc/R7EQ-57CP.

192 See notes 161-65. 
approaches. As we argued in the previous Section, research involving global search and recombination is, in economic terms, often more uncertain and costlier than that involving local searches. The psychological tests of creativity that rely on distinguishing heuristic from routine actions can thus serve as proxies of economic nonobviousness for boundary-crossing innovations: identifying those inventions where bringing together disparate technological domains also requires bridging large cognitive distances. Indeed, it is a psychologist himself who gives us the strongest endorsement of the importance of networks for innovation: "The key to understanding innovation," argues psychologist Keith Sawyer, "is to realize that the networks that bring people together are more important than the people themselves."193

\section{Examples of a Network Perspective on Innovation}

To better understand the intuition underlying the network perspective on innovation, consider two examples of recent inventions and their underlying recombinations: the home thermostat with machine learning features and the mobile phone featuring an OLED screen. The first example, a machine learning thermostat, represents a new application of the domain of machine learning to home thermostats. At the time of the invention of the first machine learning thermostat, these two technological areas (machine learning and thermostat technology) were "distant" knowledge domains that had never been recombined before. This generated an invention much different from what had come before, more likely to require the bridging of distant cognitive domains, and therefore more likely to entail high uncertainty and cost. The second of these examples represents an improvement in mobile phone screen technology, with brighter and more vibrant screens. However, the underlying combination of an electronic display and mobile phone technology is a typical one. Because there is a long tradition of combining screen technologies with mobile phones, these two technological areas are "proximate" to one another, and their recombination is less likely to involve the costly and uncertain bridging of distant cognitive domains. Taking into account the different innovation dynamics in these two inventions, reflected in their different network structures, the first invention merits patent protection more than the second. Although the network structures underlying these two inventions are quite different, the two inventions may appear remarkably

193 Sawyer, 12 Lewis \& Clark L Rev at 480 (cited in note 30 ) (emphasis omitted). 
similar to a judge or jury assessing nonobviousness: both of them are combination inventions, and both types of combination may have become quite commonplace by the time of litigation.

This same notion can be expressed visually. The three networks pictured below (Figure 1) demonstrate three different structural states. The nodes within these networks remain unchanged, but the connections between them increase. In the topmost network, we see two areas of knowledge which are wellconnected within themselves, but share no cross-community connections - and are thus separated by a structural hole. This network structure represents the two knowledge domains (for example, machine learning and thermostats) in our first example above. In the second network, we see that this structural hole has been bridged. Bringing together these disparately connected knowledge areas is precisely the sort of behavior that a network approach to nonobviousness would seek to motivate. In the final network, we see that the formerly distinct communities have become well connected, suggesting that the need to motivate further connections is lessened. This final network represents our second example, mobile screen technology, illustrating the proximity of the two knowledge domains of mobile phones and screens, at the time of the improvement.

This progression from a state in which areas of technical knowledge are relatively disconnected to a state in which they share many connections helps illustrate the need for the nonobviousness test to be able to account for changes over time in scientific and technical knowledge and norms. Human knowledge and technical capacity are in a constant state of flux. What appears nonobvious today may seem strikingly obvious in a few years' time. This temporal aspect of nonobviousness arises in both concerns about hindsight bias and in the notion that the incentives set by nonobviousness should seek to motivate the timely creation of new ideas. ${ }^{194}$ Although traditional theoretical understandings of nonobviousness acknowledge the importance of change over time in performing the obviousness analysis, they provide few analytic tools to help decisionmakers do so. One distinct advantage of a network approach to patentability is that it offers the capacity to define analytically useful measures grounded in the empirical history of innovation that can provide insight into how the distance between knowledge domains changes over time. In turn, a network approach can guide nonobviousness determinations

194 See Part I.B. 
based on the network structure at the relevant time for adjudicating nonobviousness.

In the next Part, we turn to the measurement problem. We demonstrate that the network distance between the information combinations underlying new inventions can be used to provide a signal as to how likely that invention is to be nonobvious, and show that this notoriously vague and problematic area of patent law is in fact amenable to empirical analysis. ${ }^{195}$ 
FIGURE 1: Showing three stages of network evolution as two once-distinct network areas become well-connected to one another.
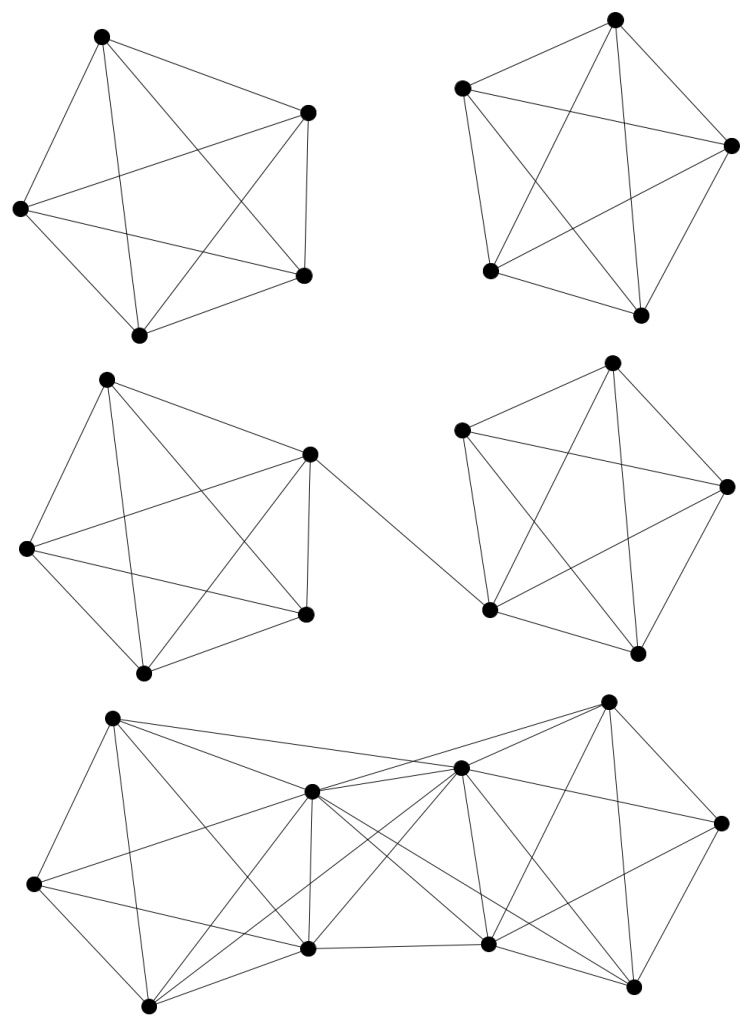


\section{DeVeloping AND Demonstrating A Network MeAsure of NONOBVIOUSNESS}

In this Part we present an empirical demonstration of how historical data on patenting trends can be used to inform doctrinal nonobviousness decisions. We first describe empirical network analysis methodology and how it can be used to understand patenting and innovation. We then show how technical classification combinations can be used to estimate the degree to which a given invention brings together proximate or distant areas of prior art (or prior knowledge). We validate our measure by comparing it against nonobviousness determinations both at the patent office and in the courts. Finally, we apply our measure to existing caselaw, demonstrating that it can be used to provide empirical insight into the nonobviousness assessment.

\section{A. Network Analysis in Legal Research}

Despite their relative novelty in empirical research methods, networks are conceptually quite simple. At their core, they represent relationships between entities. There are two concepts that are fundamental to a network- "nodes" (sometimes known as vertices) and "links" (sometimes referred to as edges). Nodes represent some sort of entity-for instance, a document, person, or category-while the links represent how they are related to one another-for instance, by citation, friendship relationship, or similarity. ${ }^{196}$

Importantly for our purposes, links need not represent simple binary relationships but can also convey the strength or "weight" of that relationship. Links between two nodes that have a high weight represent a stronger or "closer" relationship than those with a low weight. The example below shows nodes (the circles in the diagram) linked together with weighted links (the thickness of the link provides a visual representation of its weight).

196 See Whalen, 2016 Mich St L Rev at 541-42 (cited in note 48). 
FIGURE 2: Simple network diagram, showing three nodes and three links.

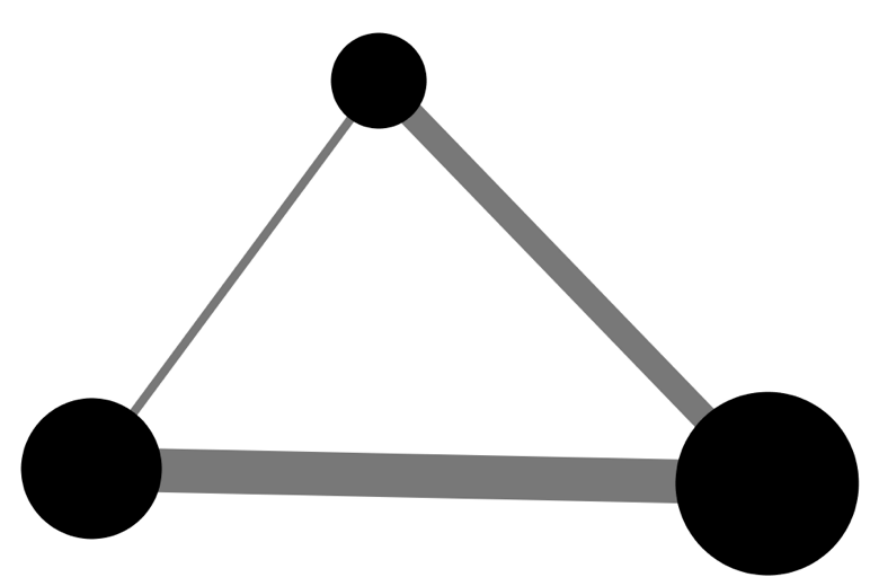

The rise of network analysis as a methodological approach has been a key development in physical, biological, and social sciences. ${ }^{197}$ Recently, scholars have begun applying network analytic techniques to legal questions. ${ }^{198}$ For example, researchers have studied the precedent citation network, in which each node represents a judicial opinion and the links between them represent citations. ${ }^{199}$ Scholars have also studied statutes using a network analytic approach, with nodes representing passages and links representing references from one portion of a law to another. ${ }^{200}$

197 See, for example, Easley and Kleinberg, Networks, Crowds, and Markets at 7-17, 567-85 (cited in note 49).

198 For an overview of the legal network literature see Whalen, 2016 Mich St L Rev at 547-54 (cited in note 48 ).

199 See generally, for example, James H. Fowler and Sangick Jeon, The Authority of Supreme Court Precedent, 30 Social Networks 16 (2008) (using networks to analyze the Supreme Court's fidelity to stare decisis over time); James H. Fowler, et al, Network Analysis and the Law: Measuring the Legal Importance of Precedents at the US Supreme Court, 15 Polit Analysis 324 (2007) (constructing a network to determine what Supreme Court precedents are most legally relevant at a particular moment in time); Ryan Whalen, Modeling Annual Supreme Court Influence: The Role of Citation Practices and Judicial Tenure in Determining Precedent Network Growth, in Ronaldo Menezes, Alexandre Evsukoff, and Marta C. González, eds, Complex Networks 169, 175 (Springer 2013) (utilizing networks to show that "precedent stability, citation age, the number of components in a year's citation subgraph and judicial tenure are all significantly related to the number of citations a year's decisions will go on to garner").

200 See generally Daniel Martin Katz and M.J. Bommarito II, Measuring the Complexity of the Law: The United States Code, 22 Artificial Intell L 337 (2014); Marios Koniaris, Ioannis Anagnostopoulos, and Yannis Vassiliou, Network Analysis in the Legal Domain: A Complex Model for European Union Legal Sources, 6 J Complex Networks 243 (2018). 
Others have studied the law school network, with law schools as nodes and links representing faculty who have trained at a given law school and now work at another. ${ }^{201}$

Legal scholars have also begun to use network analytics to study the pattern of interactions revealed by patent documents. For instance, scholars have explored how networks of patent citations demonstrate technological diffusion ${ }^{202}$ and can predict future technological developments. ${ }^{203}$ Others have examined the network of inventors linked by their prior collaborations, ${ }^{204}$ or have leveraged co-classification to identify patents that span technological boundaries. ${ }^{205}$ This work, like the broader work on networks and the legal system, is descriptive in nature, showing trends within the patent citation network and identifying emerging areas of technology or particularly valuable innovations. Our project differs both methodologically and normatively from these previous studies. By focusing on the knowledge distance between an invention's inputs, our approach uses network data to provide an empirical signal as to how likely a specific invention is to be nonobvious. ${ }^{206}$ By showing how the technological categorization co-occurrence network can be used to inform nonobviousness analysis, this Article is the first to use network analysis to inform doctrinal legal outcomes.

201 See generally Daniel Martin Katz, et al, Reproduction of Hierarchy? A Social Network Analysis of the American Law Professoriate, 61 J Legal Educ 76 (2011).

202 See generally Shann-Bin Chang, Kuei-Kuei Lai, and Shu-Min Chang, Exploring Technology Diffusion and Classification of Business Methods: Using the Patent Citation Network, 76 Tech Forecasting and Soc Change 107 (2009).

203 See generally, for example, Érdi, et al, 95 Scientometrics 225 (cited in note 51) (using a patent citation network to predict the emergence of new technological fields); Torrance and West, 20 Va J L \& Tech 466 (cited in note 52) (inferring the value of patents from their relative importance in a patent citation network); Strandburg, et al, 21 Berkeley Tech L J 1293 (cited in note 51) (studying the evolution of the patent citation network to assess whether patents were increasingly being granted for trivial improvements).

204 See generally, for example, Lee Fleming, Charles King III, and Adam I. Juda, Small Worlds and Regional Innovation, 18 Org Sci 938 (2007).

205 See generally, for example, Shi, et al, 4 PLOS ONE 1 (cited in note 170).

206 Prior work by Professor Shur-Ofry and by one of us (Laura Pedraza-Fariña) also theorized on the desirability of using network metrics to inform the nonobviousness inquiry - proposing recombination metrics based on backward citations or technological subclassifications. Neither Shur-Ofry's nor our previous work, however, developed a broader network theory of innovation or engaged with the detailed development and empirical validation of such a metric. See Shur-Ofry, 51 U Mich J L Ref at 80-84 (cited in note 53); Pedraza-Fariña, 70 SMU L Rev at 436-38 (cited in note 37 ). 


\section{B. Toward a Network Measure of Nonobviousness: Building the Patent Classification Network}

To demonstrate our network measure of nonobviousness, we built a network based on the technical classification categories used for patent documents. ${ }^{207}$ To create the patent classification network, we downloaded the cooperative patent classification (CPC) data for all patents granted since 1836.208 We then assembled a network in which nodes represent CPC subclasses, and the weighted links between them represent the number of times those subclasses co-occur on the same patents. For instance, if a granted patent is categorized as $\mathrm{H} 04 \mathrm{Q}$ (switches, relays, and selectors), G06N (computer systems based on specific computational models), and Y02B (climate change mitigation technologies) then we would add one to the link weight between each of those pairs of classes. ${ }^{209}$

Once the network is created we can begin to see the "distance" between technical areas. Those areas with strong links co-occur frequently and are thus "closer" to one another, whereas those areas with weak links or no link at all are more distantly related. However, we cannot use the simple link weights as our final distance measures because they do not control for the frequency of individual classifications. Common technical areas-such as H01L, a category for semiconductor devices and electric solid-state devices-would appear much closer to all other technical areas

207 When a patent application enters the patent examination system, patent examiners assign each application to one or more technological sections (level 1 in the classification hierarchy), classes (level 2), subclasses (level 3), groups (level 4), and subgroups (level 5). The vast majority of patents are classified into several subtechnological classes reflecting the combinatorial nature of innovation. For an extended explanation of the development of the cooperative patent classification (CPC) system, see About CPC (Cooperative Patent Classification by the European Patent Office and USPTO), archived at https://perma.cc/ESD3-XKW6. The empirical demonstration below uses classification data at the subclass level (level 3 in the classification hierarchy).

208 Data on US patents are generally available from 1836 onward due to the Patent Office fire of 1836, which destroyed the vast majority of previous patent records. Marco, et al, The USPTO Historical Patent Data Files at *12 (cited in note 40). We downloaded the Cooperative Patent Classification data from the USPTO's bulk data website. United States Patent and Trademark Office, Bulk Data Storage System: Cooperative Patent Classification (CPC) Master Classification File (MCF) for US Patent Grants, archived at https://perma.cc/7832-KZKV (accessed Dec 2017).

209 This example is drawn from US Patent No 9,245,229 covering technology related to "[o]ccupancy pattern detection, estimation and prediction," and assigned to Google, Inc. The invention couples an occupancy sensor-for detecting the number of people present at a location at different points in time-with an algorithm for detecting occupancy patterns and predicting future occupancy levels. Anthony Michael Fadell, et al, Occupancy pattern detection, estimation and predictions, US Patent No 9,245,229 (filed Jan 26, 2016), archived at https://perma.cc/BG9Y-5NT2. 
than their less common peers, simply by virtue of their commonality. What we are ultimately interested in is how often classifications co-occur relative to each of their frequencies.

To address this, we re-weighted the links between the classification nodes to represent the probability of observing that co-occurrence based on its distribution of prior co-occurrences. ${ }^{210}$ This leads to a directed network with the directed edge weights representing the probability that, given the classification in question is listed on a patent, the linked classification will also be listed. For instance, using the above example of the Google occupancy pattern detection invention, the probability of the link between H04Q and G06N co-occurring is 0.000063 when considered from the perspective of whether a patent listing $\mathrm{H} 04 \mathrm{Q}$ also includes a G06N classification, and 0.001600 when the question is posed in the opposite manner-in other words, whether a patent listing G06N also includes a H04Q classification. ${ }^{211}$ These probability scores are skewed, with the majority being quite low, suggesting that many granted patents make relatively novel combinations. ${ }^{212}$

When visualizing a network, probability scores are plotted as distance: technological classifications (nodes in our network) that are frequently recombined with a large number of other classifications (and thus are "closer" to a large number of classifications) will end up located in a "central" position in the network once all the links between technological classifications are drawn. Node size corresponds to the total strength of its relationships with other nodes, which can be interpreted as how "close" a category is to other categories, so larger nodes are closer to more other technical categories. ${ }^{213}$

210 Here, we are transforming the undirected co-occurrence network into a directed network-because each CPC class occurs with varying frequency, so the pairwise probability varies based on class. The initial network is "undirected" because links exist between two classes simply if they co-occur. Directionality gets added when we visualize the network based on the probability of each co-occurrence from each node's perspective.

211 These probabilities are calculated using the co-classification network as it existed at the end of 2016. They change over time as inventions link together different nodes within the network. Data on file with the authors.

212 See Hyejin Youn, et al, Invention as a Combinatorial Process: Evidence from US Patents, 12 J Royal Society Interface 1, 3-4 (2015).

213 To produce this figure, we have removed one CPC subclass (Y10T) that covers "Technical Subjects Covered by Former US Classification." This classification serves as a sort of "other" category. 
Visualizing this network shows that there are a few highly central nodes (Figure 3). ${ }^{214}$ The structure suggests five "communities" of nodes that share more and stronger links among one another than they do with nodes outside of their community. ${ }^{215}$ The most central substantive CPC category is H01L, which includes patents related to semiconductor devices, followed by B29C covering inventions related to plastic shaping or joining.

FIGURE 3: Class co-occurrence probability network.

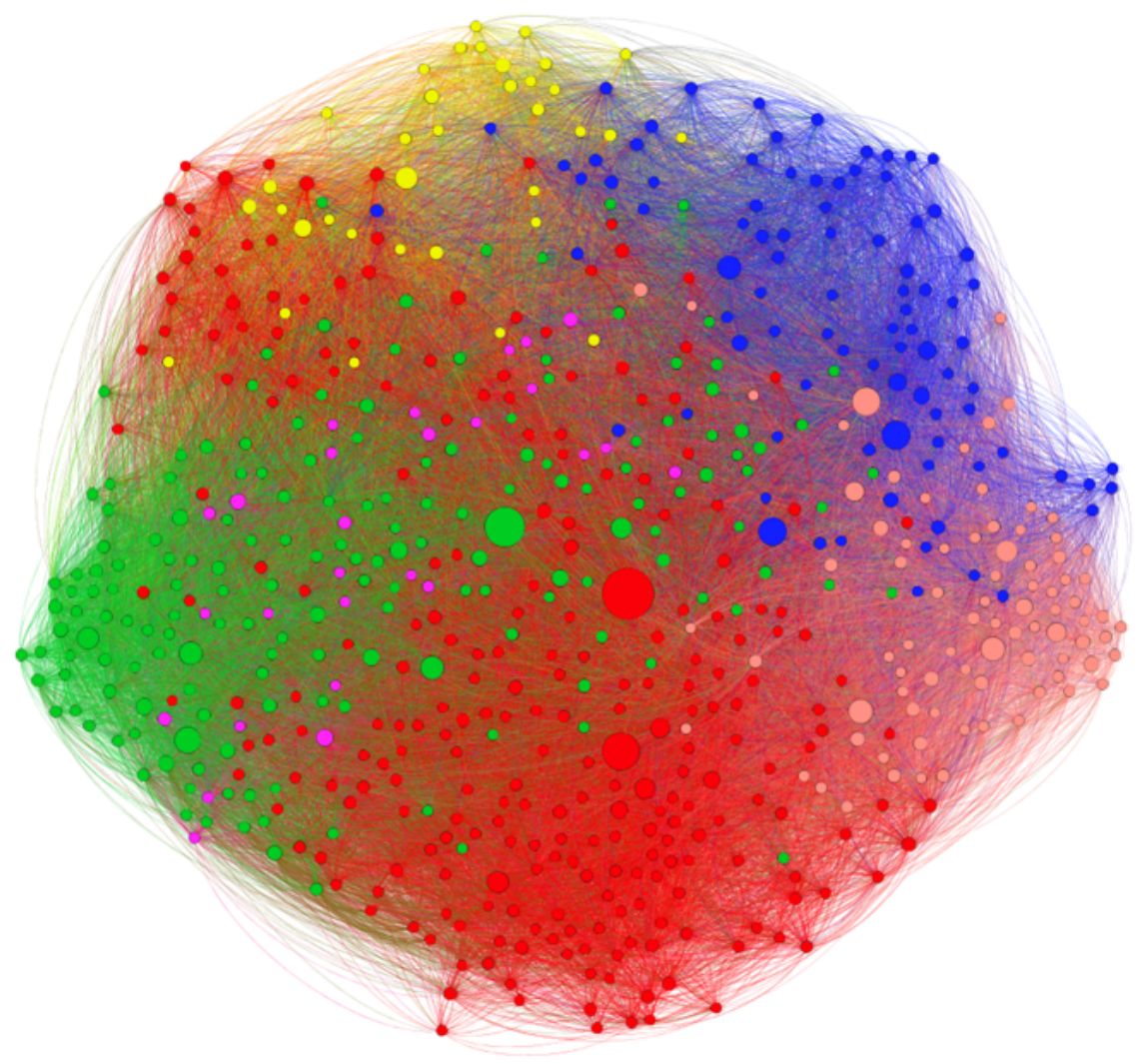

214 For a clearer visualization, this network contains only the stronger links from the full network. Any links below the 75th weight percentile were trimmed for the purpose of visualization.

215 Vincent D. Blondel, et al, Fast Unfolding of Communities in Large Networks, 2008 J Statistical Mechanics 1, 2-6 (explaining the concept of and process to find "communities"). 
We are most interested not in describing the CPC co-occurrence network as it is currently structured, but rather in using it (and the evolving connections between technological areas) to provide insight on how nonobvious a particular invention might be. The following Section will do this by using the co-occurrence probability distribution to construct a network nonobviousness score (NNOS) for each patent, and by applying the NNOS to evaluate specific inventions.

\section{Constructing and Validating the Network Nonobviousness Score}

Recall that our empirical aim is to develop a measure that can classify patents according to the distance between the technology areas recombined in each patent (or invention). As we argued in Part II, the distance between technology areas recombined in any given patent can serve as a proxy for economic nonobviousness-with patents that recombine distant knowledge being more costly, risky, and therefore nonobvious than those that recombine local knowledge. To arrive at this empirical measure-which we term a patent's "network nonobviousness score," or NNOS-we calculate the probability that a pair of categories will be listed together in a patent by comparing each subclassification pair against historical categorization co-occurrence patterns. The higher the co-occurrence probability, the closer two technology areas are in the knowledge network and vice versa. Because most patents have multiple technology subclasses, we calculate the co-occurrence probabilities for every single technology subclass pair listed in a patent document. We then choose the subclass pair with the lowest probability score (in other words, the technology pair most distant to each other) as indicative of the technological "leap" contained in the patent-this represents the NNOS. More specifically, we take the following steps to arrive at a NNOS: 
1. identify all of the invention's technological subclassifications;

2. calculate the two pairwise probabilities between each combination of two categories;216

3. identify the higher pairwise score (the "conservative recombination probability") for each combination of two categories; ${ }^{217}$ and

4. identify the pair of technology classes with the lowest conservative recombination probability score. ${ }^{218}$

This is taken as its NNOS. To enable comparisons across different technical areas, the NNOS can also be converted to a standardized $z$-score by comparing the patent's network nonobviousness score against that of inventions sharing the same primary CPC classification. A standardized $z$-score tells us how far from the mean population score a particular network nonobviousness score is. ${ }^{219}$ Positive $z$-scores represent pairwise combinations that are more frequent than the mean nonobviousness score. Negative $z$-scores represent pairwise combinations that are less frequent than the mean population nonobviousness score. ${ }^{220}$

216 For each subclass pair, there are two possible pairwise probabilities. First, the frequency with which, historically, a patent containing subclass (A) also contains subclass (B). Second, the frequency with which, historically, a patent containing subclass (B) also contains subclass (A).

217 This reflects a conservative assumption. By focusing on the higher probability score between each pair of categories, this operationalization of a NNOS leads to differing obviousness assessments in a case when the distance from categories A to B is significantly different than from B to A. Because, from a social welfare perspective, we are interested in identifying the probability that any technological community will act as a broker between two technology areas, we choose the technological community with the highest likelihood of making a particular recombination leap as our reference community.

218 These probability scores can be interpreted as proximity scores, showing how close or proximate technical areas are to one another. If they score highly, they co-occur frequently and have a high probability of being listed on the same patent-that is to say they are proximate. If the pairwise score is low, it suggests the two categories co-occur relatively infrequently and are thus distant from one another in the CPC network. We choose the two technology areas with the lowest conservative recombination probability because it represents the greatest "leap" the invention has made between technical areas.

219 Using the $z$-score (rather than the raw NNOS score) to determine nonobviousness reflects a second assumption embedded in our algorithm. We posit that the most relevant NNOS reflects a comparison between the invention at issue and the average distance routinely bridged by inventions in the same primary technical field. In fields where global search is more entrenched and "routine," market forces are likely able to induce more distant searches than in fields where global searches are rare. The latter likely require a stronger patent inducement to motivate distant recombinations.

220 See Neil J. Salkind, 1 Encyclopedia of Research Design 1662-64 (SAGE 2010). 
An example can help clarify further how we calculate the NNOS. Recall the home thermostat with machine learning features we discussed in the Introduction, and in Part II.D. This invention corresponds to US Patent No 9,256,230 claiming a "HVAC schedule establishment in an intelligent, networkconnected thermostat," and assigned to Google, Inc. ${ }^{221}$ This patent claims interactive methods for scheduling climate control. As such, it is classified within a variety of CPC categories including:

- F24F: "Air-conditioning, air-humidification, ventilation, use of air currents for screening"

- G05D: "Systems for controlling or regulating nonelectric variables"; and

- H04L: "Transmission of digital information, e.g., telegraphic communication"

These three categories give us six pairwise probability scores, and thus three conservative recombination probabilities (in bold below) as follows:

- $\mathrm{F} 24 \mathrm{~F} \rightarrow \mathrm{G05D}=\mathbf{0 . 0 3 6 9 0}$

- $\mathrm{G} 05 \mathrm{D} \rightarrow \mathrm{F} 24 \mathrm{~F}=0.03312$

- $\mathrm{F} 24 \mathrm{~F} \rightarrow \mathrm{H} 04 \mathrm{~L}=0.01116$

- $\mathrm{H} 04 \mathrm{~L} \rightarrow \mathrm{F} 24 \mathrm{~F}=0.00028$

- G05D $\rightarrow$ H04L $=0.00666$

- $\mathrm{H} 04 \mathrm{~L} \rightarrow \mathrm{G} 05 \mathrm{D}=0.00019$ 
FIGURE 4: Showing the subnetwork for the CPC subclasses listed on US Patent No 9,256,230.

Link directionality is clockwise. The "conservative recombination probability" scores taken as a reference for each pair of technology areas are as follows: H04L-F24F $=0.01116$; H04L$\mathrm{G} 05 \mathrm{D}=0.00666$; F24F-G05D $=0.03690$. The NNOS for this invention is 0.00666 .222

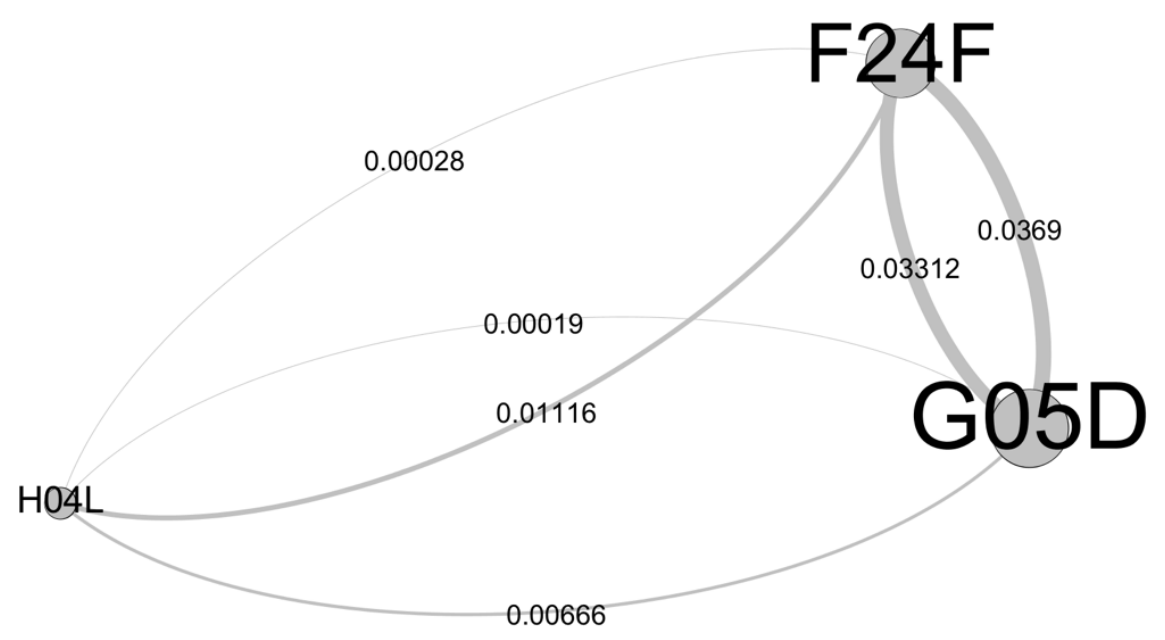

These link weights can be interpreted as showing the probability that any patent listing the classification in the first column will also list the classification in the second column. For instance, the first row shows that there's an almost 4 percent chance that a patent listing $\mathrm{F} 24 \mathrm{~F}$ (air-conditioning technologies) will also list G05D (systems for controlling nonelectric variables). That these two occur together relatively often is unsurprising, as temperature is one potential nonelectric variable. On the other hand, we see that for every 1,000 patents that lists G05D, fewer than seven also list H04L ("transmission of digital information, such as telegraphic communication"). This shows how rarely digital information transmission had been combined with nonelectric variable control as of the application's submission date, suggesting the technology claimed is relatively nonobvious. We can see this represented visually in Figure 4 as the links between F24F and G05D bring their respective categories close to one another, while

222 Data on file with the authors. 
H04L is only distantly related to either of them. ${ }^{223}$ Put differently, the combination of machine learning features with thermostat equipment was, at the time of the invention, an atypical combination suggesting a nonobvious invention. This example also provides a good illustration of asymmetry in the two pairwise probabilities between each combination of two categories. Notice how the probability that a patent listing H04L also lists G05D (0.00019) is an order of magnitude lower than the probability that a patent listing G05D also lists H04L (0.00666). To calculate the NNOS, we ignore the lowest pairwise probability score (0.00019). We can interpret these asymmetric probability scores as showing that the community of inventors involved in mechanical airconditioning and ventilation searched globally to inventions within the community of digital information transmission more frequently than the reverse. Our algorithmic design choice to ignore the lowest pairwise probability score has an impact on doctrinal outcomes, as many algorithm design choices often do. We return to a discussion on algorithmic decision-making in Part III.E and point to areas of further research in our concluding comments.

Validating the relationship between these scores and nonobviousness is not a trivial task. Because inventions lie on a continuum-from most to least creative (under psychological theories) or from slightly to extremely delayed without patent protection (under economic theories) —-where exactly to place the line between obvious and nonobvious inventions is a policy decision. This decision can be guided, but is not completely predetermined, by theory.224 However, prior nonobviousness decisions at the Patent Office and the courts do provide some signal that we can use to demonstrate whether or not our network theory of nonobviousness generally accords with prior decision-making. ${ }^{225}$

223 The $z$-score for this patent is -0.48 : half a standard deviation below the mean for thermostat patents.

224 Both proponents of psychological and economic theories recognize that theory alone does not provide a precise answer regarding where to locate the nonobviousness threshold. See, for example, Abramowicz and Duffy, 120 Yale L J at 1611 (cited in note 4) ("Ease' is, of course, a relative term, and that is its strength. The term invites judgment about the economic factors that make the process of developing something new more or less difficult."); Meurer and Strandburg, 12 Lewis \& Clark L Rev at 573 (cited in note 28) ("The choice of nonobviousness threshold to prod potential inventors toward more difficult, socially preferable research projects depends on a normative assessment of the value of social spillovers that seems highly appropriate for judicial resolution."); Amabile, $45 \mathrm{~J}$ Personality \& Soc Psychology at 361 (cited in note 151) ("It is assumed that there is a continuum of creativity from the lower levels of 'garden variety' creativity observed in everyday life to historically significant advances in literature, the arts, and science.").

225 Although our theory can offer prescriptive guidance on nonobviousness decisions, any useful legal theory must also be able to explain (and not just criticize) the shape of 
The United States Patent and Trademark Office (USPTO) provides insight into what constitutes nonobviousness every time it rejects a patent application as obvious. One would expect that, at least at the aggregate level, if our network nonobviousness measure accurately captures an aspect of nonobviousness, then we will see this evidenced in the historical record of patent application rejections that are based on $\S 103$ (obviousness) grounds. We can test for this by comparing the network nonobviousness score of applications that the USPTO rejected on $\S 103$ obviousness grounds against those that are allowed or rejected for other reasons. Doing so provides general support for our contention that the network theory of nonobviousness provides a signal as to which inventions are likely to be obvious. ${ }^{226}$ For instance, when we examine patent applications with low network nonobviousness scores-in other words, those applications we would expect to be held nonobvious-we see that $\S 103$ rejections are indeed 21 percent less frequent than we would expect by chance. Similarly, when we examine those patent applications that have high network nonobviousness scores-such as those that we would expect to be more likely to be found obvious-we see that patent examiners are indeed 9 percent more likely to find these applications obvious than we would expect. ${ }^{227}$

We further validate our measure by looking to litigated patents. To do so, we compare the NNOS of patents that were subjected to nonobviousness analysis by the Court of Appeals for the Federal Circuit (CAFC) against a random set of similarly classified patents. We find that-especially at the margins—-the court's

existing legal opinion. By validating our measure against PTO decisions, we show how our theory, in the aggregate, fits PTO's nonobviousness determinations (even though it can also offer a critique of individual decisions). See, for example, Ronald Dworkin, In Praise of Theory, 29 Ariz St L J 353, 356 (1997) (explaining the role of theory as finding the "set of principles [that] provides the best justification for the general shape of any considerable part of the law").

226 To perform this comparison, we use USPTO office action data detailed in Qiang Lu, Amanda Myers, and Scott Beliveau, USPTO Patent Prosecution Research Data: Unlocking Office Action Traits (USPTO Economic Working Paper No 2017-10, Nov 2017), archived at https://perma.cc/T8KB-SVV2.

227 These analyses were performed by first taking a random sample of patent applications, with the sample balanced across three types of PTO office actions: $§ 101$ rejections based on unpatentable subject matter, § 103 rejections based on obviousness, and allowances. We then calculate network nonobviousness scores and determine the distribution across office action types for the applications in the highest and lowest score deciles. This reveals an overrepresentation of $\S 103$ rejections in the high decile. A chi-squared test demonstrates that overrepresentation is significantly higher than one would expect by chance, $x^{2}=10.79, \mathrm{p}<0.01$. Similarly, the lowest decile shows an underrepresentation of $\S 103$ rejections than we would expect to observe at random. 
decisions agree with our predictions based on litigated patents' NNOS. Those litigated patents which had the highest ten scores (demonstrating a high probability of observing their class combinations) were all held to be obvious, while those with the lowest ten scores (demonstrating a low probability of observing their class combinations) were held to be nonobvious seven times out of ten. ${ }^{228}$

In the aggregate, our measure agrees both with historical patent examination and litigation outcomes. However, there will be instances of both agreement and disagreement between our measure and traditional approaches: these are the important cases in which the network theory of nonobviousness and its associated NNOS can "criticize" existing law and provide useful guidance.

\section{Applied Examples of the Network Nonobviousness Score}

In this Section we apply our measure to specific patent disputes, demonstrating how it can help shed light on whether or not a given invention should be considered nonobvious. There are four possible outcomes when making a determination as to whether or not a given invention is nonobvious. One could correctly identify it as nonobvious, correctly identify it as obvious, incorrectly identify it as nonobvious, or incorrectly identify it as obvious. ${ }^{229}$ That is to say, the PTO (or courts) can grant a patent on an invention that is indeed patentable (true positive), grant a patent on an invention that is not patentable (false positive), reject an application for an invention that is in fact patentable (false negative) or reject an application in which an invention is indeed not patentable (true negative).

Table 1 shows these four possible outcomes, and maps them onto their classification outcome categories.

\footnotetext{
228 Data on file with the authors.

229 In machine learning parlance, these model outcomes are often conveyed in a confusion matrix that is used for model evaluation. See Kai Ming Ting, Confusion Matrix, in Claude Sammut and Geoffrey I. Webb, eds, Encyclopedia of Machine Learning and Data Mining 260 (Springer 2d ed 2017). False positives and false negatives are analogously referred to as Type I and Type II errors in statistical hypothesis testing.
} 
TABLE 1: FouR POSSIBLE OUTCOMES OF NONOBVIOUSNESS ADJUDICATION

\begin{tabular}{l|l|l|} 
& $\begin{array}{l}\text { Invention is in } \\
\text { fact nonobvious } \\
\text { (patentable) }\end{array}$ & $\begin{array}{l}\text { Invention is in } \\
\text { fact obvious } \\
\text { (not patentable) }\end{array}$ \\
\hline $\begin{array}{l}\text { Finding of } \\
\text { nonobviousness } \\
\text { (application } \\
\text { granted) }\end{array}$ & $\begin{array}{l}\text { True Positive } \\
\text { (Correct Decision) }\end{array}$ & $\begin{array}{l}\text { False Positive } \\
\text { (Incorrect Decision) }\end{array}$ \\
$\begin{array}{l}\text { Finding of } \\
\text { obviousness } \\
\text { (application } \\
\text { rejected) }\end{array}$ & $\begin{array}{l}\text { False Negative } \\
\text { (Incorrect Decision) }\end{array}$ & $\begin{array}{l}\text { True Negative } \\
\text { (Correct Decision) }\end{array}$ \\
\hline
\end{tabular}

We apply our NNOS to examples of each of these decision outcome types by examining Federal Circuit nonobviousness decisions after KSR.

1. True negative: Western Union v MoneyGram.

In the "true negative" category the invention in question is obvious, and the decision maker correctly determines it to be so. This will lead to either a rejection of the patent application, or an invalidation of the patent if it has already been granted. For an example of this type of outcome, we can look to the Federal Circuit's decision in Western Union Co $v$ MoneyGram Payment Systems, Inc. ${ }^{230}$ This dispute arrived at the Federal Circuit from the Western District of Texas after MoneyGram appealed a jury finding of patent validity and infringement.

Western Union's invention claimed a method to process money transfers without using paper forms. Money transfer customers would phone in their order, whereupon the details would be entered into a computer database. ${ }^{231}$ The customer could then proceed to a retail money transfer location and, using a code phrase associated with her previous phone order, a local customer service representative could access the details and accept payment for the transfer. ${ }^{232}$

In litigation, Western Union identified a key technological advance that distinguished this claimed method from previous

\footnotetext{
230626 F3d 1361 (Fed Cir 2010).

231 Id at $1363-66$.

232 Id.
} 
money transfer systems. They argued that the use of a keyboard to enter and retrieve order details from an electronic transaction fulfillment device (ETFD), as opposed to using a fax machine to send details to the retail location, constituted a substantial step from the state of the art. ${ }^{233}$ MoneyGram argued that-given the fact that there was prior art from another money transfer franchise detailing a method to phone in an order, and subsequently visit a branch that would have been faxed the order details to complete the order - the addition of using a keyboard and an internet-connected computer to the method would have been obvious to one skilled in the art. Ultimately, the Federal Circuit agreed with MoneyGram, finding that "applying computer and internet technology to replace older electronics has been commonplace" and that using a networked ETFD "was obvious because it amounted to no more than applying the use of the Internet to existing electronic processes at a time when doing so was commonplace." 234

This analysis is supported by a network approach. Examining the network nonobviousness score of the most important patent in question (US Patent No 6,488,203) shows that the invention draws on highly proximate technology areas-subclasses G07F (relating to automated teller machine (ATM) technologies) and G06Q (relating to currency transfer and financial technologies). These two areas have a raw network nonobviousness score of 0.53 , which demonstrates that they co-occur very frequently, almost 2.5 standard deviations higher than the average for financial transfer technologies. ${ }^{235}$ This bolsters the court's findings and suggests that it was quite reasonable for the court to suggest that an ordinarily skilled artisan would have been likely to combine the inputs that the invention draws upon. In a context such as that presented in the Western Union case, the NNOS can provide valuable empirical insight to identify obvious invention. Indeed, the NNOS can increase efficiency and save on litigation costs if deployed by the PTO at the examination stage - thus avoiding the grant of obvious patents.

233 Id at $1363,1368$.

234 Western Union, 626 F3d at 1370, citing Muniauction Inc v Thompson Corp, 532 F3d 1318, 1327 (Fed Cir 2008).

235 In comparing network nonobviousness scores, we compare the focal patent against other inventions sharing the same main CPC classification. This provides some control for the fact that some technologies are inherently more likely to combine technical categories. We can then compare how many standard deviations the focal patent score is from the mean of this distribution. This provides a comparable score across patents. This data is on file with the authors. 
2. False negative: Nike $v$ Adidas.

A false negative situation arises when the invention in question is not obvious, yet is found to be unpatentable for obviousness reasons. To see how this might play out in practice, we can look to the dispute in Nike, Inc $v$ Adidas $A G .{ }^{236}$ In this case, Nike owned a patent on a textile-based shoe upper created using a knitting process, and commercialized as Nike's "Flyknit" technology.237 The innovation in this type of footwear manufacturing technology was the use of yarn and fabric variations, as opposed to mesh, to engineer "a featherweight, formfitting, and virtually seamless upper," 238 which was also environmentally friendly. ${ }^{239}$ According to invention stories in popular media, Nike assembled a team of computer scientists, engineers, and designers who took "a knitting machine for socks and sweaters and re-engineer[ed] it to produce the upper part of a sneaker." ${ }^{240}$

Adidas challenged Nike's patents in an inter partes review proceeding. Nike responded with a request to cancel their existing claims and replace them with substitute claims. The Patent Trial and Appeals Board (PTAB) rejected Nike's motion to insert substitute claims, finding that Nike had failed to establish their patentability, and holding the claims obvious. ${ }^{241}$ On appeal, the Federal Circuit agreed with the PTAB's reasoning that all of the elements of the invention were present in three prior art references, and that there was a motivation to combine those elements. ${ }^{242}$

A network perspective, however, provides evidence that Nike's invention combines distant technology areas. The knitted shoe upper invention combines four CPC subclasses, including the rarely combined A43D (characteristic features/parts of footwear) and D04B (knitting). The raw conservative recombination probability between these two subclasses is 0.0002 , with the $z$-score almost one standard deviation below average, suggesting

236812 F3d 1326 (Fed Cir 2016).

237 Id at 1329-30. The patent in question is US Patent No 7,347,011.

238 Evelyn L. Brannon and Lorynn R. Divita, Fashion Forecasting 194 (Fairchild 4th ed 2015).

239 See Nike, 812 F3d at 1338-39.

240 How Nike Flyknit Revolutionized the Age-Old Craft of Shoemaking (The Guardian, Nov 27, 2013), archived at https://perma.cc/8UMB-6QKD (noting how it required teams of programmers, engineers, and designers to create the proprietary technology needed to create the knitted upper).

241 Nike, 812 F3d at 1332.

242 Id at $1336-38$. Despite agreeing with the Board that a PHOSITA would have a motivation to combine the three prior art references, the Federal Circuit vacated and remanded the Board's obviousness determination on the grounds that the Board failed to explicitly consider evidence of secondary considerations of nonobviousness. 
that previous inventors had rarely combined knitting technologies with footwear technologies. In turn, the rarity of this recombination provides strong evidence of nonobviousness, especially when coupled with publicly available invention stories. ${ }^{243}$ These stories describe the many years of costly research and development required to develop the Flyknit manufacturing process-indicating that the large technological distance between knitting and footwear also reflects a large cognitive distance between these two areas, whose recombination required risky and costly team research.

The PTAB had held that Nike's invention was simply an obvious combination of existing prior art covering both a method of producing footwear and of knitting a helmet. ${ }^{244}$ Nike, however, argued that the references were sufficiently different from each other that one skilled in the art would not have thought to combine them. ${ }^{245}$ The low NNOS score supports Nike's position here. The helmet knitting prior art references were both categorized to D04B, a technology area that, as we saw above, had rarely been combined with footwear inventions. Moreover, both helmet knitting references dated back to 1939. ${ }^{246}$ This raises the question of why they had yet to be combined if indeed there was a motivation to combine them with footwear technologies.

3. False positive: WBIP $v$ Kohler.

A false positive situation arises when the invention in question is in fact obvious, yet it is found to be nonobvious and thus patentable. This would be detectable with a NNOS approach when a patent has a high NNOS, indicating a highly local search and recombination, yet is still held nonobvious. ${ }^{247}$

243 See, for example, Brannon and Divita, Fashion Forecasting at 194 (cited in note 238); How Nike Flyknit Revolutionized the Age-Old Craft of Shoemaking (cited in note 240); Tyler Watamanuk, Nike Found a Way to Make Flyknit Even Better (GQ, Mar 30, 2018), archived at https://perma.cc/25MA-TV3T; Eric Siemers, Nike's Flyknit Has a Sustainable Business Story to Tell (Portland Bus J, June 20, 2014), archived at https:// perma.cc/6MKX-Y5G7.

244 Nike, 812 F3d at 1332, 1335-38.

245 Id at 1335.

246 Id at 1336.

247 In Federal Circuit cases for which nonobviousness was at issue, a high NNOS almost always corresponds with invalidation of the patent at issue. This suggests that courts frequently reach the correct decisions on litigated patents with high NNOS. It also suggests, however, that use of the NNOS at the examination stage would efficiently lower societal costs (including litigation costs) associated with the grant of invalid patents. 
$W B I P, L L C v$ Kohler $C^{248}$ is a representative example. The patent at issue covered marine generator carbon monoxide reduction technology. ${ }^{249}$ On appeal, Kohler (the infringing party) argued that, because the invention simply recombined elements already present in nonmarine engine technology, the invention should be considered obvious. ${ }^{250}$ Because the court was presented with conflicting reports of both a presence and absence of a motivation to combine these preexisting elements into the invention at issue, it turned to secondary considerations of nonobviousness to guide its decision-making. Relying on these considerations, including praise for the product and its commercial success, the Federal Circuit ultimately rejected Kohler's obviousness argument. ${ }^{251}$

This example illustrates one of the greatest challenges in determining nonobviousness, especially for inventions that combine a variety of prior art references. An invention that simply recombines known prior art elements is not necessarily obvious. In fact, as our search and recombination model of innovation makes clear, most inventions can be thought of as the recombination and rearrangement of preexisting knowledge elements. Under an economic approach, the difference between an obvious and a nonobvious recombination is that the former would have taken place without patent incentives, while the latter requires the inducement of a patent. Currently, courts rely on a variety of subjective and unclear tests to determine whether a combination invention such as that at issue in the WBIP case requires the inducement of a patent. This evidence includes a number of secondary considerations, such as evidence of commercial success and praise from others that were pivotal in the court's nonobviousness determination in this case. The NNOS can supplement these tests with empirical evidence. More specifically, the NNOS can provide crucial insight into whether the invention recombined distant knowledge elements (a type of recombination more likely to be risky and costly, and therefore more likely nonobvious) or local knowledge elements (a type of recombination more likely to be routine and cheap, and therefore more likely obvious).

Examining the patent at issue in the $W B I P$ case shows a relatively high NNOS, suggesting that the prior art areas were in fact proximate-approximately half a standard deviation closer

\footnotetext{
248829 F3d 1317 (Fed Cir 2016).

249 Id at $1324-25$.

250 Id at 1326 .

251 Id at $1334-35,1337$.
} 
than the average invention. ${ }^{252}$ Although this score alone does not conclusively demonstrate that the invention did not require the inducement of a patent (and therefore was obvious), it does suggest that an ordinary artisan would have had easy access to the prior art ultimately combined to make up the invention. Absent additional persuasive evidence of a high cost of recombination (driven, for example, by hidden technological difficulties in recombining the proximate preexisting technology), the high NNOS should tip the scales toward a finding of obviousness.

4. True positive: InTouch v VGo.

A "true positive" nonobviousness determination arises when an invention is in fact not obvious and the relevant decision maker correctly reaches this conclusion. We can see an example of this scenario in InTouch Technologies, Inc v VGo Communications, Inc. ${ }^{253}$ This case arose after InTouch sued VGo for infringing one of its patents covering remote telepresence robot technologies. The invention in question was designed to allow for remote "visits" to a hospital patient, with the telepresence robot controlled by a remote device such as a tablet computer. ${ }^{254}$

VGo argued that InTouch's patent was invalid as obvious, claiming that it was based on an obvious recombination of preexisting inventions. ${ }^{255}$ At the lower court, the jury had accepted VGo's expert testimony concerning obviousness and had invalidated a number of InTouch's patent claims as obvious combinations of existing prior art.256 However, on appeal, the Federal Circuit found that VGo's expert's testimony was flawed and exhibited hindsight bias. ${ }^{257}$ Rather than analyzing "what one of skill in the art would have understood as of 2001," VGo's expert had "simply opined what a skilled artisan could accomplish in 2011." 258 The Federal Circuit held that this hindsight bias, combined with the lack of import given to the objective indicia of

252 The patent at issue in WBIP was US Patent No 7,314,044. At the subclass level, this invention implicates three categories that are all quite proximate to one anotherF01N (covering "gas-flow silencers or exhaust apparatus for machines or engines"), F02B (covering "internal-combustion piston engines"), and F02D (covering "control for internal combustion engines").

253751 F3d 1327 (Fed Cir 2014).

254 Id at $1332-34$.

255 Id at 1335.

256 Id at 1337, 1348.

257 InTouch, 751 F3d at 1348-52.

258 Id at 1352. 
obviousness that InTouch provided, to merit overruling the jury's finding of obviousness. ${ }^{259}$

Our NNOS can act as a decision-making aide in cases such as this. Because our score is calculated using the data available at the time an invention is created, it is not susceptible to hindsight bias. ${ }^{260}$ Rather, it provides an objective and empirical assessment of how likely a given combination is, based on the contemporary evidence available in the patent record. Calculating the NNOS on one of the key patents in question ${ }^{261}$ in the InTouch case supports this position. Doing so shows a score more than a full standard deviation below the average network nonobviousness score $(z=-1.23)$ for telemedicine patents, demonstrating that the invention in question brought together technical areas that were comparatively rarely combined. This supports the Federal Circuit's reasoning in this case and suggests that this was indeed a nonobvious invention.

Thus far, this Part has used historical CPC co-classification data to develop a network measure of nonobviousness. We then validated this approach by comparing its results to USPTO patent prosecution data and recent Federal Circuit decisions. Finally, we applied our network nonobviousness score to four actual patent disputes and showed how the measure can help guide decision-making by identifying likely true positive, false positive, true negative, and true positive decisions. The next Section explores how to more precisely integrate a network approach to nonobviousness into the current doctrinal framework for patent nonobviousness.

\section{E. Integrating the Network Nonobviousness Score into the} Current Doctrinal Framework

Modeling innovation as a search and recombination process reveals two distinct types of inventions: (1) those emerging from local search and recombination processes and (2) those emerging

259 Id at $1353-54$.

260 Evidence suggests that hindsight bias commonly distorts patent law reasoning, and is difficult to guard against. See Mandel, 67 Ohio St L J at 1393-95 (cited in note 26).

261 The relevant patent is US Patent No 6,925,357. This patent combined a variety of subclasses, including B25J (manipulators; chambers provided with manipulation devices) and $\mathrm{H} 04 \mathrm{~N}$ (pictorial communication). These two classes-one focused on devices that physically manipulate objects and one that focuses on telecommunication-had rarely been combined, which from a network nonobviousness perspective suggests patentability. 
from global search and recombination processes. As we discussed in detail in Part II, local searches-all things being equal-tend to be more predictable and less costly than global searches. Local searches are also likely to lead to incremental improvements of existing technology rather than technological leaps. The NNOS provides an empirical tool to differentiate the first (local) from the second (global) type of inventions. Were we to design a doctrinal framework for nonobviousness from the ground up, we would focus first on identifying whether the invention at issue is the result of a local or a global search and recombination. Or, to be more precise, we would want to know where the invention at issue falls on the spectrum of searches ranging from extremely local to extremely global — when compared to a "typical" invention in the invention's primary technological field. Our empirical measure, the NNOS, provides precisely this type of signal: when expressed as a $z$-score, it classifies inventions according to whether they recombine knowledge inputs that are more or less distant than the average or typical invention in a particular technology class. The concepts of local and global search, however, can also be integrated into the current doctrinal framework as developed by the Court in Graham and KSR.

The nonobviousness framework consists of four structured steps. First, the court must determine the "scope and content of the prior art." 262 Prior art relevant for nonobviousness purposes comprises the collection of all publicly available knowledge that an ordinary artisan (or PHOSITA) would rationally consult when attempting to carry out her invention. ${ }^{263}$ This relevant or "analogous" prior art will therefore exclude some types of existing knowledge that are not within the grasp of an ordinary artisan. The second step in the nonobviousness inquiry requires identifying the PHOSITA from whose perspective the differences between this analogous prior art and the claimed invention must be evaluated. ${ }^{264}$ Both the analogous art and the PHOSITA inquiries can be reconceptualized in network terms. In essence, they seek to identify the types of knowledge that are proximate (in a network sense) to a PHOSITA's core technological expertise. The key and often most complex third step requires a determination of whether these differences between the invention and prior art are "obvious" from a PHOSITA's perspective. Finally, step four

262 Graham, 383 US at 17.

263 See In re Bigio, 381 F3d 1320, 1325 (Fed Cir 2004); In re Winslow, 365 F2d 1017, 1020 (CCPA 1966).

264 Bigio, 381 F3d at 1325-26. 
requires consideration of those "secondary" considerations of nonobviousness, if present, first announced by the Court in Graham. ${ }^{265}$

As we argued in Parts I and II, we adopt an economic interpretation of nonobviousness, which emerges as the best interpretation of the Court's opinions in Graham and KSR. The Court in $K S R$, however, left unclear how judges should attempt to measure existing market and design forces, and when market forces may be sufficient to tip the balance toward obviousness. Within this economic framework, as we elaborated in Part II, the distance traveled by an invention in recombining knowledge inputs serves as a proxy for nonobviousness. We propose that the NNOS should serve as a threshold "sorting" mechanism, both at the PTO and during litigation, that allows for more focused analysis of these two distinct types of innovation (local and global). Below, we explore in more detail how to incorporate the NNOS, and a network analysis more broadly, into the structured nonobviousness inquiry.

1. The "scope and content of the prior art": NNOS as a threshold sorting mechanism.

The Federal Circuit uses two criteria to determine whether prior art is analogous: "(1) whether the art is from the same field of endeavor, regardless of the problem addressed and, (2) if the reference is not within the field of the inventor's endeavor, whether the reference still is reasonably pertinent to the particular problem with which the inventor is involved." 266 Both criteria present difficulties for the fact finder. First, technological "fields of endeavor" are not fixed over time: disciplines and subdisciplines both merge and subdivide over time. Second, whether a PHOSITA would consult a particular reference outside her field of endeavor is, at bottom, a network inquiry. It can be rephrased as: Does a PHOSITA have reasonable access to the network of knowledge and expertise to which the outside reference pertains? Absent a snapshot of the network of interactions among the relevant technological fields, fact finders applying their "common sense" have little objective data to guide their conclusions, which in turn risks the introduction of hindsight bias. ${ }^{267}$

\footnotetext{
265 Graham, 383 US at $17-18$.

266 Bigio, 381 F3d at 1325.

267 See Part I.B.
} 
Our proposed NNOS relies on the "proximity" of technical fields to estimate how likely a combination of those fields is. A similar approach can be used to inform the determination as to what is, and what is not, the "same field." By measuring the frequency of recombination between the technical classifications of both a given prior art reference and patent, our measure provides empirically grounded insight into whether the prior art reference and the invention at issue are likely part of the same field. Our measure has a singular advantage over current ad hoc methods:268 it is dynamic and can capture changes in fields and subfields over time, while providing a snapshot of the connections among technical areas at the relevant time for assessing nonobviousness.

Similarly, our measure can help determine whether a prior art reference is reasonably pertinent to an invention's creation. The current test for pertinence is whether a prior art reference "logically would have commended itself to an inventor's attention in considering his problem." 269 This test provides little guidance to a decision-maker, as it is as difficult to determine what would have logically commended itself to an inventor as it is to determine what was pertinent. However, from a network perspective, the inquiry here is fundamentally one of proximity. It can be rephrased as: Does a PHOSITA have reasonable access—or is her technological field reasonably proximate-to the network of knowledge and expertise to which a particular prior art reference pertains? Those prior art references that are "close" enough to the area within which the inventor is working are pertinent, because an inventor will have sufficient access to them.

Ultimately, however, our network theory upends the brightline categories of "analogous" and "non-analogous" art, and "same" or "different" field. These categories implicate a classification into well-defined buckets. Technological areas, however, are not so neatly defined. Rather, a network map reveals a continuum of connections among them ranging from more to less proximate.

Instead of thinking of prior art as "analogous" and "nonanalogous," a more productive approach is to divide inventions themselves into those arising from local searches and recombinations, and those arising from global searches and recombinations. The NNOS can serve as a rough sorting mechanism, with high

268 The PTO determines analogousness both by looking to cross references within the technical classification scheme, and by considering similarities and differences between the structure and function of the claimed invention and the prior art in question. See Manual of Patent Examining Procedure (MPEP) § 2141.01(a).

269 In re Clay, 966 F2d 656, 659 (Fed Cir 1992). 
scores representing frequently recombined local searches and low scores representing infrequently recombined global searches. This initial sorting inquiry can then guide further analysis according to innovation type - as opposed to simply eliminating "non-analogous" art from consideration, as is the current practice.

a) Global search and recombination patents. Very distant searches and recombinations, with very low (in other words, negative) NNOS $z$-scores that are more than a full standard deviation below the mean score for that technological field, should constitute strong evidence of nonobviousness. This presumption of nonobviousness, however, can be rebutted if the large technological distances bridged by the invention do not correlate well with cognitive distance, or if such cognitive distance is already rapidly shrinking because of market demands and other social forces. Evidence tending to show a disparity between technological and cognitive distance would include, for example, the existence of routine, readily available scripts or techniques to recombine the two distant fields. Network analysis can also detect whether two distant technological fields are, in fact, already converging toward each other prior to the invention. This can be done by observing the network distance between fields over time. Rapid convergence can be catalyzed by sudden upticks in market demand for a particular type of innovation, or the application of technological advances from a third community to bridge existing cognitive distances. The advantage of a network approach is that the effect of these market demands and exogenous technological advances can be clearly visualized as two fields rapidly converging toward each other prior to the invention at issue. The bar for nonobviousness on a combination invention drawing on rapidly converging fields should be set somewhat higher, because there is a decreased need to incentivize those inventions through patent grants.

Inventions that recombine "somewhat" distant fields (less than a standard deviation away from the mean invention) present a more complicated scenario. Here, the NNOS as currently designed provides a weaker signal of nonobviousness. Other objective indicia of nonobviousness, such as failure of others to develop the invention and skepticism from core members of the innovator community, should serve as additional evidence that the recombination at issue was risky and that it bridged cognitively distant areas. In addition, there are other potential ways of operationalizing a search and recombination model of innovation. One of them includes accounting for recombination complexity by measuring the number of different $\mathrm{CPC}$ classes combined in a single 
invention. In the next Section, we briefly discuss alternative ways of calculating the NNOS, which could all be used in concert to provide a more accurate network measure of nonobviousness.

b) Local search and recombination patents. Very local search and recombinations, with NNOS $z$-scores that are more than a full standard deviation above the mean score for that technological field, should raise a red flag at the patent examination stage and during litigation. Inventions with high NNOS scores are often those low-risk, low-cost, routine inventions that do not require the inducement of a patent. Note that among litigated patents before the Federal Circuit for which nonobviousness was at issue, a very high NNOS almost always corresponded with invalidation of the patent at issue. ${ }^{270}$ At the examination stage, tagging this type of patent for careful investigation may reduce the grant of low-quality patents and save on wasteful litigation.

Nevertheless, there are factors other than search and recombination distance that can influence how costly and risky an invention is. More specifically, some inventions arising from closely related technological fields require the generation of new knowledge available only through lengthy and costly experimentation. There is a key difference between low-cost/low-risk local searches and recombinations and their high-cost/high-risk counterparts. In the first category are inventions that simply combine easily searchable and recombinable preexisting knowledge elements like pieces of a puzzle. A good example is the invention at issue in Western Union (our "true negative" example). This invention drew upon extremely proximate areas of knowledge, almost 2.5 standard deviations higher than the average for financial transfer technologies. ${ }^{271}$ And the specific feature that differentiated this invention from similar ones-the use of a keyboard to process transactions-requires no major research and development investiture to implement. In the second category, preexisting knowledge elements provide only a starting point for intensive research. A good example of this type of innovation is the search for new chemical entities to treat a particular disease. Available knowledge usually provides only "clues" as to the type of chemical structure that may in fact provide an effective treatment. Finding that chemical structure requires costly (if sometimes routine) research that often requires the inducement of a patent.

270 See Part III.C.

271 Data on file with the authors. 
The NNOS is not a magic bullet. It does not provide a number that instantly tells the fact finder whether to grant or deny a patent. Together with the search and recombination theory of innovation on which it is based, however, the NNOS provides objective signposts to guide the types of innovation-specific questions examiners and judges should ask when determining nonobviousness. These signposts are strongest for very low NNOS scores representing global searches and recombinations: here the NNOS, standing alone, can be a good proxy for nonobviousness. The NNOS is also useful to weed out simple combination inventions that rely on very proximate knowledge, as was the case in Western Union. The case for using the NNOS as a proxy is weakest, however, when the NNOS is close to the average for a particular technological area, revealing "somewhat" distant or "somewhat" proximate recombinations of technological knowledge. In these latter cases, fact finders should rely more heavily on additional network measures, which we discuss in the next Section, or on other "secondary considerations of nonobviousness," to which we turn to below in Part III.E.3.

2. Defining the level of skill in the art.

Defining the skill level and knowledge content of a PHOSITA is a crucial step, not only in the nonobviousness inquiry, but also in infringement determinations. ${ }^{272}$ A PHOSITA is a "typical" inventor, part of the invention's primary field community. A PHOSITA's ability to creatively bring together distant knowledge domains is determined, at least in part, by the baseline recombination distance typical of that particular field, a feature that can be accurately captured by the NNOS expressed as a $z$-score. Because a standardized $z$-score tells us how far from the mean population score a particular network nonobviousness score is, each score takes into account the baseline level of "creativity" of a particular technological community.

While the NNOS centers on mapping relationships between technological units, the knowledge content of a PHOSITA may also be determined by building a network of inventors. Mapping relationships between inventors-for instance by linking together those who collaborate or work on highly similar inventions-can generate an innovation social network that provides insight into

272 See, for example, Graver Tank and Manufacturing Co $v$ Linde Air Products Co, 339 US 605, 609 (1950) (demonstrating that a finding of infringement via the doctrine of equivalents depends on whether the PHOSITA would have been aware of the equivalence). 
the traits of an "ordinary" inventor within a given technical field. An inventor social network would allow those tasked with defining a PHOSITA to canvass a technical "neighborhood" and determine the average skills, training, and expertise of those working in the area. ${ }^{273}$

Finally, what constitutes an invention's "primary" field poses a series of interesting questions, linked to defining the community to which the PHOSITA belongs. The PTO routinely assigns inventions to a "primary" CPC classification category, and we take this category as an invention's primary field for the purpose of calculating an invention's NNOS as a $z$-score. ${ }^{274}$ Nevertheless, for inventions that bridge together two (or more) separate technologies, it is unclear at the outset which field among them should be chosen as the "primary" field. Should it be the field (or technology area) in which the invention at issue has, in fact, originated? Should it be the field with the highest pairwise recombination probability-in other words, the field most likely to make the recombination giving rise to the invention based on the NNOS? Should the test instead be based on the market for products embodying the invention? Or should the relevant unit of analysis be a team having ordinary skill in the art that has expertise in both areas? These questions are undertheorized and underresearched in the legal literature. A network approach makes these issues salient, generating important questions for further research concerning how to precisely define the relevant innovation community in which the PHOSITA resides.

\section{Secondary considerations of nonobviousness.}

The aftermath of KSR has seen a rise in fact finders' reliance on those "secondary" considerations of nonobviousness first articulated by the Court in Graham. ${ }^{275}$ This development flows logically from $K S R$ 's flexible, expansive approach that insists on taking into account the real-world context of innovation but provides limited guidance on how to do so. Secondary considerations of

273 See MPEP § 2141.03. Constructing such a network is beyond the scope of this paper, but we use it here as an illustration of the capabilities of a general network approach to innovation.

274 For a description of how the PTO chooses the "field of invention," and the crucial importance of this choice to multiple patent law doctrines, see generally Saurabh Vishnubhakat, The Field of Invention, 45 Hofstra L Rev 899 (2017).

275 See Natalie A. Thomas, Secondary Considerations in Nonobviousness Analysis: The Use of Objective Indicia Following KSR v. Teleflex, 86 NYU L Rev 2070, 2090, 209495 (2011). 
nonobviousness naturally anchor the nonobviousness inquiry to empirical real-world events. ${ }^{276}$

Many secondary considerations can be understood in network terms. Specifically, considerations such as "failure of others," "long felt but unmet need (for the invention)," "teaching away (from the invention)," and "skepticism" provide relevant evidence for understanding the technological and cognitive complexity involved in the search and recombination process. For example, evidence of "skepticism" or "teaching away" can serve as additional compelling evidence that market or social forces would have dissuaded a particular community from making the particular knowledge recombination leading to the invention-making that path riskier. "Failure of others" and "long felt but unmet need" provides additional evidence that the recombination at issue was cognitively complex. As we emphasized in Part II, bridging large cognitive distances between knowledge domains requires assembling and managing a team of diverse expertise-a proposition that is often both risky and costly and that therefore increases an invention's economic nonobviousness. In our proposed framework that begins by categorizing inventions as arising from local or global search and recombination processes, these secondary considerations still play an important supporting role-supplementing the initial signal provided by the NNOS.

Our measure could also be integrated into the current doctrinal framework as a secondary consideration itself. The objective nature of our proposed measure, tied to the distance between technological classes at the time of invention, makes it particularly well suited as a strong secondary consideration. While many may disagree about the extent to which a market demand was "long-felt but unmet" or how much of its success a successful product owes to a patented component, our measure leaves little room for contested interpretation. ${ }^{277}$ We advance this possibility as a "second-best" approach to our preferred policy proposal that would use the NNOS as a sorting mechanism at the outset of the nonobviousness inquiry.

276 In Graham the Court stated that the "secondary considerations . . might be utilized to give light to the circumstances surrounding the origin of the subject matter sought to be patented." Graham, 383 US at 17-18.

277 Of course, what ultimate legal conclusions on patentability to draw from a particular network nonobviousness score is open to contextual judicial interpretation since no objective measure can provide a single definitive answer to nonobviousness. This is the case in large part because determining the threshold level of innovativeness required to obtain a patent is a policy decision that cannot be conclusively answered with our networkbased algorithm (or any other existing test). 
F. Advantages and Limitations of a Network Approach

The method described above to calculate a NNOS is only one of many possible ways to take a network approach toward operationalizing the concept of nonobviousness. We offer it here as a conceptually straightforward demonstration of how thinking of innovation as occurring within networks of information can help provide insight into how obvious or not a given invention is. In practice, the algorithmic design choices underlying a network nonobviousness score must address a variety of challenges, including asymmetrical distances between fields, differing levels of complexity between inventions, and inventions that largely occur within a single domain. We briefly touched upon these design choices in Part III.C and we expand upon them below.

The issue of asymmetrical distance occurs when the apparent network distance between two categories varies greatly depending on directionality. 278 This can occur when inventions listing category A frequently list category $\mathrm{B}$, but those inventions listing category B list category A with less relative frequency. In our proposed method above, we have dealt with this issue by opting to take what we call the "conservative recombination distance." This essentially ignores the lowest recombination probability between the pair and opts instead to select the higher, more proximate of the two scores. As such, it sets a higher network nonobviousness bar. There are alternate methods of dealing with asymmetrical distance, such as averaging the two scores or taking the minimum or maximum. Each choice has implications for how network nonobviousness is determined, and thus on the patentability assessment.

Differing levels of complexity-defined here as the number of different technology areas an invention draws upon-also raise questions that should be addressed when designing an appropriate network nonobviousness measure. Those inventions that draw largely on a single domain of knowledge and demonstrate limited evidence of recombination are less well suited for a nonobviousness assessment from a network perspective. There are certainly inventions that draw primarily on a single knowledge domain that an efficient patent system should consider nonobvious despite the fact that they do not integrate distant knowledge. For instance, many drug developments likely fit within this category. They may be categorized into only one or a few highly proximate areas, but should nonetheless not be automatically barred

\footnotetext{
278 See Part III.E.1.
} 
from patentability because of this. As we explained in Part III.E, in such cases of very local searches, the NNOS alone cannot answer the nonobviousness question. Rather, fact finders will need to rely upon additional factors, such as whether the invention required the generation of new knowledge available only through lengthy and costly experimentation.

In addition to challenges raised by low-complexity inventions, the variation in degrees of complexity between inventions can also raise nonobviousness measurement issues. For instance, if relying only on the minimum nonobviousness score between any two categories to characterize an invention's nonobviousness, an invention integrating only categories A and B may score the same when compared to a second invention integrating both A and B as well as many other categories. From an innovation theory perspective, it seems likely that the second invention recombining many more categories is more cognitively and technically complex and therefore less obvious. Thus, a fine-tuned empirical measure of nonobviousness should be designed to account for these varying degrees of complexity. This could be done in a variety of ways, most of which would supplement the univariate example measure defined above with more dimensions of nonobviousness, such as the total number of categories integrated or the sum of the total distance between integrated categories.

There are multiple other potential nonobviousness signals that a "production ready" network measure could leverage. For instance, citation relationships between patents can be used to infer which preceding technologies the invention in question draws upon. In perhaps its simplest form, a citation dimension could be added to the NNOS by examining the technical classifications of the cited prior art-assessing nonobviousness based on the distance between the cited prior art fields. Alternatively, citations can be used to generate a citation network. In a citation network, the documents-in this case cited prior art referencesform the nodes, and the citations between them form the links. Those inventions that cite to distant prior art references combine technical information that is highly dissimilar, suggesting that the underlying invention is nonobvious in much the same way that combining rarely combined CPC classes does.

In addition to the technological classification distance, one could also incorporate a measure of the "semantic distance" between the claimed invention and the prior art. By semantic distance we mean the similarity of the meaning of the language used to describe the invention and detail its claims with the language 
used in prior art documents. ${ }^{279}$ In conjunction with other data, such as patent prior art citation data, ${ }^{280}$ semantic distance can provide insight into the different areas of knowledge that an invention combines. ${ }^{281}$ This in turn can provide useful insight into how likely-and thus obvious - we expect such a combination to be. ${ }^{282}$ Adding a semantic component to our network nonobviousness score could help strengthen the signal, while also making it more difficult to "game" the measure by strategically assigning technical classifications. Semantic measures also provide a more nuanced measure that is less subject to the inherent coarseness of metadata measures that treat all content within a given category as semantically identical. ${ }^{283}$

Finally, a network nonobviousness score could take into account the source of the knowledge recombined in an invention by examining networks of inventors. ${ }^{284}$ Modern innovation is increasingly produced by teams of researchers, ${ }^{285}$ and those teams are increasingly likely to bring together diverse sets of knowledge. ${ }^{286}$ In much the same way as we examine the recombination frequency of technical classifications to provide insight into nonobviousness, the social structure of collaboration can reveal the likelihood of a particular combination of expertise and experience. Unusual collaborations, much like rare technical combinations in our NNOS, are more likely to involve the type of risky and costly

279 Semantic similarity can be measured using a variety of natural language processing (NLP) methods. See generally Peter D. Turney and Patrick Pantel, From Frequency to Meaning: Vector Space Models of Semantics, $37 \mathrm{~J}$ Artificial Intell Rsrch 141 (2010).

280 See, for example, Strandburg, et al, 21 Berkeley Tech L J at 1344 (cited in note 51) (proposing that "[p]ath length measures [that rely on citation distance] may provide a more fine-grained (and complementary) measure of technological closeness than metrics that use the number of overlapping subclasses in the USPTO classification system").

281 See, for example, Whalen, $47 \mathrm{Rsrch}$ Pol at 1341-42 (cited in note 167).

282 Others have used semantic measures for similar applications such as detecting patent infringement. See generally Hyunseok Park, Janghyeok Yoon, and Kwangsoo Kim, Identifying Patent Infringement Using SAO Based Semantic Technological Similarities, 90 Scientometrics 515 (2011).

283 Whalen, 47 Rsrch Pol at 1337 (cited in note 167).

284 Doing so would entail mapping the social network of inventor collaborations, wherein inventors are connected to one another if they have previously collaborated. With the network mapped, one could calculate the likelihood of observing particular types of links, or the distance collapsed by adding new collaboration links.

285 See Stefan Wuchty, Benjamin F. Jones, and Brian Uzzi, The Increasing Dominance of Teams in Production of Knowledge, 316 Science 1036, 1037 (2007) (finding that teams have increasingly produced the most cited scholarship and patents).

286 Alan L. Porter and Ismael Rafols, Is Science Becoming More Interdisciplinary? Measuring and Mapping Six Research Fields over Time, 81 Scientometrics 719, 740-41 (2009). 
recombination of distant cognitive domains that requires the inducement of a patent.

Regardless of which dimensions an empirical nonobviousness measure takes into account-whether it be co-classification data, citation data, social network data, or other signals-policymakers must remain cognizant of the potential for patent applicants to game the system. Like many legal questions, the question of nonobviousness can be considered from the perspective of rules versus standards. ${ }^{287}$ Laws exist not within a dichotomous regime, but rather occupy a point somewhere along a rules-to-standards spectrum. ${ }^{288}$ Our proposal for a data-driven NNOS would nudge the nonobviousness inquiry in the "rule" direction from its current point toward the "standard" side of the spectrum. By making the law of nonobviousness more explicit and thus rule like, such an approach would also make it somewhat easier for applicants to game the system by attempting to ensure that their patent applications performed well in network nonobviousness terms. For example, applicants may intentionally draft their applications in such a way as to accentuate their suitability for multiple distant categories.289 Although the potential for gaming will likely increase under any quantifiable nonobviousness test, that should not alone preclude policymakers from considering its adoption. Rather, those using a tool like the NNOS approach must be made aware of the potential for gaming; they should be flexible in applying the score to the patentability assessments; and they should not use such an approach uncritically. Importantly, relying on multiple network measures of nonobviousness, such as the ones outlined above, should significantly reduce the ability of patentees to game the system, as it becomes increasingly harder to game multiple different measures simultaneously.

287 See generally, for example, Duncan Kennedy, Form and Substance in Private Law Adjudication, 89 Harv L Rev 1685 (1976) (describing the evolution of rules to standards in contract law); Kathleen M. Sullivan, The Supreme Court, 1991 - Foreword: The Justices of Rules and Standards, 106 Harv L Rev 22 (1992) (discussing the Supreme Court justices' preferences for rules versus standards).

288 Russell B. Korobkin, Behavioral Analysis and Legal Form: Rules vs. Standards Revisited, 79 Or L Rev 23, 30 (2000) ("The legal forms of rules and standards, then, are better understood as spanning a spectrum rather than as being dichotomous variables.").

289 Gaming the system by intentionally drafting patent applications so that the invention falls under two distant categories, however, is not without risks for the patentee. For example, ensuring an application falls within a category outside the invention's main classification may require adding language reflecting additional technology (a "limitation" in the language of patent drafting) that may subsequently narrow the scope of the claim and make it easier for others to design around the patent, especially if such limitation is not essential to the invention at issue. 


\section{CONCLUSION}

The nonobviousness doctrine enjoys a dubious place of honor in the patent law canon as at once the most important and the most vague of all patent law doctrines. This Article has explored how a network perspective on patentability, grounded in a search and recombination model of innovation, can both clarify the doctrine's theoretical foundations and provide an objective empirical measure of nonobviousness.

This Article made three key contributions. First, it identified and then supplied an important missing piece in both psychological and economic analyses of patentability: an underlying theory of innovation. Building upon network studies of innovation, we argued that conceptualizing innovation as a search and recombination process across knowledge networks provides important innovation-specific insights that can improve upon current economic and psychological understandings of patentability. Under a search and recombination model, firms invent by carrying out either local or global searches and recombinations of existing knowledge. Because global searches and recombinations require teams of diverse expertise to bring together cognitively distant knowledge domains, they tend to be riskier and more costly than local searches, which often rely on well-trodden routines to recombine easily accessible knowledge. From this perspective, we argued that the nonobviousness doctrine should seek to incentivize those costly and risky inventions that bring together cognitively distant technological domains.

This network perspective nuances current economic understandings of nonobviousness by providing innovation-specific factors (namely, search and recombination distances) that deeply influence economic risk and cost. It also demonstrates how psychological understandings of creativity-while ultimately not able to stand alone as normative justifications of nonobviousness - can serve as valuable proxies for economic nonobviousness by helping identify those inventions that bridge large cognitive distances. This reconceptualization of psychological views of nonobviousness as proxies for economic nonobviousness for some types of inventions also brings clarity to judicial decisions, which often blend economic and psychological justifications without providing an explicit rationale for doing so.

Second, building upon this theoretical understanding of nonobviousness, we empirically developed a "network nonobviousness score" (NNOS) that relies on the distance between the technical areas recombined in each individual invention. Because it is 
grounded in empirical innovation data, the NNOS can be calculated for any date, and is thus able to account for the constant state of change in the innovation ecosystem. When applied to litigated nonobviousness cases, our measure identified several cases that have been incorrectly decided under a network theory of patentability, while also providing empirical support for many of the Federal Circuit's other nonobviousness decisions. ${ }^{290}$ We proposed a novel doctrinal framework that relies on the NNOS as an initial sorting mechanism both to distinguish global from local inventions and to guide further analysis based on the different innovation dynamics underlying these two innovation types.

Finally, our algorithmic approach contributes to broader debates in the legal literature about the rise of computational law. Despite the potential of an empirically informed nonobviousness measure to aid patentability decision-making, policymakers must consider the implications of how algorithmic design, and the data used to validate any measure of patentability, may affect the results. Recent years have brought increased adoption of computationally assisted decision-making technologies, which in turn has given rise to concerns about the biased results that these seemingly objective technologies can lead to. ${ }^{291}$ These biases can have various causes, but the two most important in our context are (1) the result of biased data or (2) biased measure-design.292 Biases resulting from data inputs can arise because many algorithmically enabled decision-making or decision-support tools rely on existing data to classify new cases as they arise. This can lead to entrenchment of existing biases inherent in the existing data, as it becomes applied to new cases. In the context of our proposed NNOS, biased data inputs could arise if the classification data used to estimate nonobviousness is systematically biased. Indeed, as the product of human decision-making, it is quite possible that these classifications are biased and the data is almost certainly imperfect. This is one of the reasons we advocate for a multivariate approach-for example by including citation, semantic, and social network data in a NNOS-so as to triangulate the nonobviousness estimate and reduce measurement error.

290 See Part III.D.

291 See, for example, Solon Barocas and Andrew D. Selbst, Big Data's Disparate Impact, 104 Cal L Rev 671, 677-93 (2016). For discussion of patent-specific issues relating to the prospect of increased use of computationally assisted decision-making tools, see Arti K. Rai, Machine Learning at the Patent Office: Lessons for Patents and Administrative Law, 104 Iowa L Rev 2617, 2636-40 (2019).

292 See Barocas and Selbst, 104 Cal L Rev at 677-84 (cited in note 291). 
Another potential source of bias arises from measure design. Here, the concern is not that the computationally assisted decision-making tool is reifying existing biases in an input or training dataset, but rather that some element of the way the algorithm is designed may itself internalize a particular perspective on the construct being measured and thereby propagate that particular perspective. We have illustrated how this could arise in the context of the NNOS when we considered alternative ways of operationalizing the concept of network nonobviousness. There is a large body of research providing theoretical support for the notion that the network distance between an invention's knowledge inputs provides a signal correlated with the risk and cost of achieving that particular invention-and therefore with its economic nonobviousness. Nevertheless, there is no single correct method to measure network distance. For the purposes of this Article, we picked the most distant pair of technological categories in any given invention as that invention's NNOS. This choice results in a measure that privileges inventions which combine two highly distant knowledge areas over those that may combine many moderately distant knowledge areas. This is what we called the "invention complexity" problem in our algorithmic design. A differently designed measure could lead to dramatically different nonobviousness results. For instance, defining a NNOS as the sum of the distance between all technology areas recombined would lead to a measure that indicates nonobviousness when an invention combines many technology areas, even if they are only moderately distant from one another, while potentially indicating obviousness when an invention recombines only two highly distant areas.

That such a minor variation on how one operationalizes network nonobviousness could lead to such divergent results accentuates the importance of measurement tool design. It also emphasizes the importance of algorithmic transparency, as only those with intimate knowledge of specific algorithm design choices would be able to identify these potential design biases. Ultimately, in the case of NNOS design, as in most cases, there will be no single perfect design. That said, lest the perfect become the enemy of the good, the potential of a computationally assisted decision-making tool should not preclude its adoption. Evidence suggests that the current patentability decision-making at the 
PTO is highly costly and error prone. ${ }^{293}$ Any tools that could help examiners be more efficient and accurate in their decision-making process should be considered.

In the case of a NNOS metric as proposed in this Article, implementing it effectively will require that we remain aware of its limitations and potential biases and be open to iteratively updating and improving the measure. To do so, it would be best to involve multiple and diverse stakeholders in the measure design, implementation, and improvement processes. By taking into consideration the views of patent owners, applicants, examiners, and the public, policymakers will be better able to construct a tool that is responsive to the interests of these varied stakeholders, and, by treading a middle road between their often-competing views on how patentability should be defined and measured, is more likely to be implementable.

Implementing such a tool will represent a major step in patent policy. Not only will it signal the patent system's willingness to integrate some of the findings resulting from decades of network-oriented research on innovation and creativity, but it will also mark a willingness to more effectively use the vast troves of patenting data that the patent system currently produces, and subsequently underutilizes in patentability assessments.

293 See generally Michael D. Frakes and Melissa F. Wasserman, Does the U.S. Patent \& Trademark Office Grant Too Many Bad Patents?: Evidence from a Quasi-Experiment, 67 Stan L Rev 613 (2015). 